Canadian

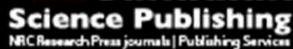

Canadian Geotechnical Journal Revue canadienne de géotechnique

\title{
Observations of hydraulic fracturing in soils through field testing and numerical simulations
}

\begin{tabular}{|r|l|}
\hline Journal: & Canadian Geotechnical Journal \\
\hline Manuscript ID & cgj-2015-0193.R1 \\
\hline Manuscript Type: & Article \\
\hline Date Submitted by the Author: & 22-Jun-2015 \\
\hline Complete List of Authors: & $\begin{array}{l}\text { Chang, Muhsiung; National Yunlin University of Science \& Technology, } \\
\text { Construction Engineering } \\
\text { Huang, Ren-Chung; National Yunlin University of Science \& Technology, } \\
\text { Graduate School of Engineering Science \& Technology }\end{array}$ \\
\hline Keyword: & $\begin{array}{l}\text { hydraulic fracturing, fracturing pressure, soil grouting, field testing \& } \\
\text { monitoring, numerical simulation }\end{array}$ \\
\hline &
\end{tabular}




\section{Observations of hydraulic fracturing in soils through field testing and numerical simulations}

Muhsiung Chang ${ }^{1}$ and Ren-Chung Huang ${ }^{2}$

1 Corresponding author

Department of Construction Engineering, National Yunlin University of Science \& Technology,

Taiwan.

Postal address: No.123, Section 3, University Road, Touliu City, Yunlin County, Taiwan.

Email address: changmh@yuntech.edu.tw

Tel: +886-5-534-2601 Ext.4718

Fax: +886-5-531-2049.

2 Graduate School of Engineering Science \& Technology, National Yunlin University of Science \& Technology, Taiwan.

Postal address: No.123, Section 3, University Road, Touliu City, Yunlin County, Taiwan.

Email address: g9910809@yuntech.edu.tw 


\section{ABSTRACT}

Hydraulic fracturing is a potential cause for the leakage of earth dams or the loss of fluid in drilling and field permeability testing. Hydraulic fracturing is also a major concern on the effectiveness of soil grouting. Although hydraulic fracturing has been adopted in petroleum industry for decades for oil recovery in rock formations, studies on the fracturing in soils are relatively few and inconclusive. The aim of this study is to provide more insights on the mechanism of hydrofracturing in soils through a field grouting trial and numerical simulation. We observe hydraulic fracturing in soils during this field trial as predicted by generally accepted groutability requirements. The hydraulic fractures are found vertically developed up to the ground surface. Numerical simulations show the hydraulic fracturing is easier to be initiated in anisotropic stress conditions, where the minor principal stress is the key factor. Numerical simulations also demonstrate significant compressions and shears during injection, suggesting the mechanism of fracturing in soils would be a shearing type. Based on this study, we propose a punching and splitting mode for the hydrofracturing in soils. The associated relationship for fracturing pressure estimation is verified and found in good agreement with the cases examined.

Keywords: hydraulic fracturing, fracturing pressure, soil grouting, field testing \& monitoring, numerical simulation. 


\section{Introduction}

Hydraulic fracturing is a potential threat to the leakage of earth dams and the loss of fluid during borehole drilling and field permeability testing (Bjerrum et al. 1972; Jaworski et al. 1981; Sherard 1985; Lo and Kaniaru 1990; Djarwadi et al. 2014). Hydraulic fracturing is also a primary concern on the effectiveness of ground improvement by grouting. In rock and petroleum engineering, hydraulic fracturing has been used as a technique for oil and gas recovery as well as for in-situ stress measurement (Mitchell and Van Court 1992; Jaworski et al. 1979; Yokoyama et al. 2014). In recent decades, hydraulic fracturing has also been adopted in environmental applications for landfill gas recovery and contaminant mitigation purposes (Mitchell and Van Court 1992; Wong and Alfaro 2001; Murdoch and Slack 2002).

Hydraulic fracturing is a subject of research in academia and industries, mainly applied to rock formations in deep ground. Studies of hydraulic fracturing in soils, however, are relatively rare, due to soils generally exhibiting a much different type of deformation and strength characteristics, as well as the fracturing mechanism, than those of the rocks (Bruno et al. 2001). The study herein is therefore aimed at providing more insight on the hydraulic fracturing in soils. In the following, we present our research findings based on results of a field grouting trial and the associated numerical simulations. A mode of hydraulic fracturing in soils and an empirical relationship for fracturing pressure estimation are also proposed and verified at the end of this paper. 


\section{Previous studies on hydraulic fracturing in soils}

\section{Injection mechanism and penetrability}

Injection mechanisms in soils generally involve permeation, compaction and fracturing, which depend on various factors including soil type, injection fluid type, or injection pressure and rate. (Hausmann 1990; Mitchell and Van Court 1992). For suspension type injection fluids, a lower limit of the particle size ratio between soil and injection fluid (i.e., penetrability or groutability ratio) is required to ensure the injection to be permeable (Kravetz 1958; Mitchell 1982; Akbulut and Saglamer 2002; Axelsson et al. 2009). Otherwise, the compaction or fracturing mechanism would be expected. For solution type injection fluids, however, a decrease in gel-time of injection fluid, a decrease in permeability of soil, or an increase in injection rate, would lead an injection to cause more fracturing (Mori et al. 1992; Choi and Yanagisawa 1996). In studies of compaction grouting, Warner (1992) and Graf (1992) indicated the inclusion of bentonite or other colloidal clays would increase the mobility of the grout, thus promote a fracturing type of mechanism, and render the compaction of ground to be ineffective.

\section{Fracture initiation and propagation}

Hydraulic fracturing is identified as one of the possible causes of failure of Teton Dam. Ac- 
cording to the Independent Panel which reviewed causes of failure, hydraulic fracture is defined as "the condition leading to the creation and propagation of a thin physical separation in a soil or rock mass as a result of fluid pressures which are excessive in comparison to the stresses within the soil or rock mass." (Jaworski et al. 1979). The process of hydraulic fracturing in soils has been studied in laboratory testing as well as by numerical simulations, which generally indicate considerable deformations in soils around the injection hole would be required prior to the initiation of fracturing (Hou and Bai 1991; Chang 2004; Wang et al. 2009). Several theories on the fracture initiation are proposed in the literature, which can be broadly categorized into a tensile mode (Haimson 1968; Vaughan 1971; Whittaker et al. 1992; Alfaro and Wong 2001) and a shearing mode (Morgenstern and Vaughan 1963; Mori and Tamura 1987; Panah and Yanagisawa 1989; Alsiny et al. 1992; Yanagisawa and Panah 1994). Other types of fracture initiation are also available, such as liquefaction-like of fracturing or off-shoot mode, etc. (Chang 2004). Bjerrum et al. (1972) proposed theories on hydraulic fracturing based on different scenarios in which each of the stress components in soils adjacent to the borehole is exceeded by the injection pressure. Different assumptions of the fracture mode would lead to dissimilar estimates of the fracturing pressure.

Once initiated, hydraulic fractures would develop and propagate in the ground. Based on studies in the literature, the orientation of fractures would be parallel to the direction of the maximum principal stress, or the plane upon which the minimum principal stress acts (Yanagisawa and Panah 1994; Wang et al. 2009; Shimizu et al. 2011; Nasehi and Mortazavi 2013). 


\section{Hydrofracturing pressure in soils}

Several theories of hydrofracturing pressure $\left(p_{f}\right)$ have been proposed based on various modes of fracturing. Hydrofracturing pressures, considering a tensile mode and derived using elastic or empirical approaches, were presented by Haimson (1968), Vaughan (1971), and Jaworski et al. (1981) with a general form of $p_{f}=m \sigma_{\min }+\sigma_{t}$; where $\sigma_{\min }$ and $\sigma_{t}$ are the minimum principal stress and the tensile strength of soil, respectively, and $m$ is a coefficient ranged 1 2. Haimson (1968) indicated the coefficient $m$ of 2 for impermeable rocks and $>1$ for permeable rocks. Based on laboratory test results, Jaworski et al. (1981) suggested $m$ in the range of 1.5 1.8.

Mori and Tamura (1987) proposed a hydrofracturing theory based on a shearing mode and a plastic yielding approach. Assuming no tensile crack and no fluid penetration in clays, they established a relationship: $p_{f}=\sigma_{\min }+q_{u}$; where $q_{u}$ is the unconfined compression strength of the clay.

Other theories of hydraulic fracturing considering a shearing mode and a plastic yielding approach are also available (Morgenstern and Vaughan 1963; Panah and Yanagisawa 1989; Lo and Kaniaru 1990; Yanagisawa and Panah 1994). By extending to a 3D stress condition, Yanagisawa and Panah (1994) derived a hydrofracturing pressure with the form: $p_{f}=\left(1.5 \sigma_{\min }-0.5 \sigma_{\max }\right)(1+$ $\left.\sin \phi_{u}\right)+2 c_{u} \cos \phi_{u}$; where $c_{u}$ and $\phi_{u}$ are the undrained shear strength parameters of the clay.

By employing a passive earth pressure concept, Hou and Bai (1991) set up a relationship for the hydrofracturing pressure as $p_{f}=\sigma_{v} K_{p}+2 c \sqrt{K_{p}}$; where $K_{p}=\tan ^{2}\left(45^{\circ}+\phi / 2\right), \sigma_{v}$ is the verti- 
cal pressure at the depth of injection, and $c$ and $\phi$ are shear strength parameters of the soil.

Bjerrum et al. (1972) considered three modes of fracture initiation in drained conditions: (1) if the circumferential stress $\left(\sigma_{\theta}^{\prime}\right)$ in soil adjacent to the borehole has been exceeded first, then the hydrofracturing pressure is ${p^{\prime}}_{f}=(1 / v-1)\left[(1-\alpha) \sigma_{h}^{\prime}+\sigma_{t}^{\prime}\right]$ and a vertical crack is expected; (2) if the radial stress $\left(\sigma_{r}^{\prime}\right)$ in soil has been exceeded first, then the hydrofracturing pressure is $p_{f}^{\prime}=$ $(1-v)\left[(2+\beta-\alpha) \sigma_{h}^{\prime}+\sigma_{t}^{\prime}\right]$ and a vertical crack is expected; (3) if the overburden pressure $\left(\sigma_{v}^{\prime}\right)$ has been exceeded first, then the hydrofracturing pressure becomes $p_{f}^{\prime}=\sigma_{v}^{\prime}$ and a horizontal crack will be formed. The factors $\alpha$ and $\beta$ in the above relationships depend on the compressibility of soils, $v$ is the Poisson's ratio of soils, and $\sigma_{h}^{\prime}$ and ${\sigma^{\prime}}_{t}$ are the effective horizontal earth pressure and the effective tensile strength of soils, respectively.

Hydrofracturing pressures have also been derived based on the cavity expansion theory (Vesic 1972; Massarsch 1978). By considering a saturated undrained clay, Massarsch (1978) provided an expression for the cavity expansion fracturing pressure as $p_{u}=\tau_{f} \ln \left\{1.36 E /\left[\tau_{f}(1+v)\right]\right\}$; where $\tau_{f}$ is the undrained shear strength of clay, and $E$ and $v$ are the Young's modulus and Poisson's ratio of clay, respectively.

For hydraulic fracturing in undrained conditions, Mitchell and Soga (2005) stated a tensile mode could be assumed if the soil around the injection borehole behaves elastically, and the fracturing pressure is $p_{f}=2 \sigma_{\min }-2 u_{0}+\sigma_{t}$, with a slope of 2 between $p_{f}$ and $\sigma_{\min }$, where $\sigma_{t}$ is the tensile strength of soil and $u_{0}$ is the initial pore pressure. Alternatively, a shear mode could occur if 
the soil around the borehole boundary reaches plastic state and the fracturing pressure becomes

$p_{f}=\sigma_{\min }+s_{u}$, with a slope of 1 between $p_{f}$ and $\sigma_{\text {min }}$, where $s_{u}$ is the undrained shear strength of soil. However, the slopes of the above $p_{f}$ relationships would likely fall between $1 \sim 2$, due to the fact that neither of the assumed conditions actually occur in reality.

Jaworski et al. (1979) indicated a lower bound to the fracturing pressure could be as low as the sum of the minimum principal stress and the tensile strength of the soil, i.e., $\sigma_{\min }+\sigma_{t}$. The upper bound would be the pressure required to cause cavity expansion, as proposed by Massarsch (1978).

Andersen et al. (1994) conducted a comparison of various theories of hydrofracturing pressure, and found errors of the calculated pressures with respect to the measured values ranging from: $-32 \%$ $\sim+32 \%$ (elasticity theories), $-47 \% \sim+36 \%$ (initial yield theories), $-37 \% \sim+98 \%$ (empirical relationships), and $+76 \% \sim+150 \%$ (cavity expansion theories). Andersen et al. (1994) also proposed a new approach in consideration of the non-linearity properties of soils and the induced pore pressure due to injection. This new approach appeared to significantly improve prediction accuracy, with the calculated errors ranging $-7 \% \sim+4 \%$ of the measured values.

\section{Field grouting program}

A field grouting trial is conducted with the aims to reveal the mechanism and development of hydraulic fractures in soil strata due to grouting, as well as to provide the information on injection 
pressures and rates required for hydraulic fracturing. As shown in Fig. 1, the field grouting site consists of an area of $6 \mathrm{~m} \times 6 \mathrm{~m}$, which is then excavated in stages, to a depth of about $8.5 \mathrm{~m}$, for mapping of grout traces after the grouting. A grout hole $G$ is installed closer to the NW corner of the site, in order to maximize the SE area for activities of mapping and testing. Fig. 1 also shows the soil profile encountered at the site.

The field grouting program includes injection of three types of grout into the soil strata. Table 1 indicates the type and composition of the grouts adopted, in which the GCB and CB grouts are of suspension type, while SA40 grout is a solution. Compared with generally accepted groutability limits $\left(G_{R}=D_{15}^{\text {soil }} / D_{85}^{\text {grout }} \geq 15\right)($ Kravetz 1958; Mitchell 1982), the particle size ratios of the suspension grouts adopted appear too small to ensure a permeation grouting. Accordingly, we expect the injection mechanism of this grouting trial would be primarily controlled by the fracturing. Fig. 1 also shows the depth intervals for grout injection, the location of injection points, and the sequence of grouting steps. Details of this grouting program are referred to Chang et al. (2009).

The grouting is facilitated by the use of a $5 \mathrm{~cm}$-dia. sleeve tube (tube à manchette; TAM) with the injection openings and sleeve covers of $33.3 \mathrm{~cm}$ in spacing. As illustrated in Fig. 2, a $10 \mathrm{~cm}$-dia. borehole is drilled and a TAM is installed in the center of the hole. The annular space between the TAM and the borehole is then filled with a cement-bentonite (CB) grout (or seal) as a protection layer for the TAM. The CB grout, same material as adopted for the grouting, is cured for 1 day prior to the subsequent grouting activities. During the grouting, an injection tube is inserted into the TAM at 
the depth of an injection point (opening), with its upper and lower ends closed (within the TAM) by the inflated rubber packers. By increasing the injection pressure, the rubber sleeve (on the TAM) bursts, and the grout breaks through the CB seal and then enters into the ground. The injection pressure and flow are measured at the pump exits, as shown in Fig. 2, away from the injection point in the ground. The pressure required for fracturing the ground at the injection point would therefore not be the same as measured at the pump exit on the ground. In accordance, the pump exit values would need to be corrected by subtracting the resistances of the rubber sleeve and CB seal, as well as the friction along the grout pipe, in order to obtain the actual hydrofracturing pressure and rate for the ground.

After the grouting, the site is excavated step-wise with five $1 \mathrm{~m}$-high benches started from depths $3.5 \mathrm{~m}$ to $8.5 \mathrm{~m}$. As shown in Fig. 1, two vertical and one horizontal faces in each of the excavated benches are carefully mapped on the traces of the injected grouts.

\section{Results of field grouting observations}

\section{Injection mechanism}

Generally, the observed mechanisms of injection in this field trial are dominant by fracturing, as indicated in Table 1, which are correctly predicted by the commonly accepted penetrability (groutability) requirements based on particle size ratios (e.g., $D_{15}^{\text {soil }} / D_{85}^{\text {grout }}$ ) (Kravetz 1958; Mitchell 1982). 
Also of note is the on-site observation on the enlargement of annular space between borehole and

TAM, suggesting the soil proximate to the grout hole has been compacted due to the injection.

Fig. 3 illustrates the mapped traces of grout on the ground surface and the three faces in each of the excavation stages. On the ground surface, grout emergences are recorded at various stages of grouting. During the GCB grouting stage (Grouting Depths 4.2 6.2 m), grout emergences are clustered around the grout hole and along a diagonal extended from the grout hole to the site boundary in approximately SES direction. This diagonal trace of grout indicates the projection of hydrofracturing of ground on the surface due to the grouting.

At the excavation depth range of $3.5 \sim 4.5 \mathrm{~m}$, where the GCB grout is injected in a clay (CL) layer, two hydraulic fractures are obvious with one exiting from the grout hole. Similar situations are found at the excavation depth range of $4.5 \sim 5.5 \mathrm{~m}$, where fracturing by GCB grout is the dominant mechanism of injection.

At the excavation depth ranges of 5.5 6.5 $\mathrm{m}$ and $6.5 \sim 7.5 \mathrm{~m}$, where $\mathrm{CB}$ grout or SA40 grout is injected in a sandy (SM) or silty (ML) layer, permeation type of injection becomes obvious in addition to the fracturing mechanism found in these soils. This situation appears in relation to the nature of the grouts. The CB grout is a suspension with a long gel-time of 24 hours. The long gel-time would promote permeation prior to the final setting in spite of the fracturing mechanism of the suspension grout. The SA40 grout is a solution but with a short gel-time of 3 5 minutes. The short gel-time would tend to hinder the permeation character and lead to a minor fracturing mechanism for 
the solution grout.

The mapped grout traces on the ground surface and from all of the excavation stages may suggest several nearly vertically-developed fracture surfaces that initiate from the injection points of the grout hole and exit upwards to the ground surface during the grouting. These nearly vertical fractures imply the in-situ soil strata should be normally consolidated, with minor principal stresses of the ground in approximately horizontal directions.

\section{Injection pressure and rate}

A typical example of injection pressure $(p)$ and injection rate (or grout flow, $q$ ) vs. time records and the combined $p \sim q$ curves are shown in Fig. 4 . We notice a peaking in the injection pressure $\left(p_{b, o}\right)$ is obvious along with an increase in the grout flow, signifying a breakthrough of all resistances and an initiation of hydraulic fracturing. The injection pressure will suddenly drop to a steady value $\left(p_{f, o}\right)$ with a constant flow rate normally greater than that for the peak pressure, indicating a progressive development of the fracturing in soils. The injection pressure will finally decrease to a residual value $\left(p_{\text {fric }}\right)$ at the cease of grout flow, representing the friction remained in the grout pipe system.

To determine the actual pressure required for fracturing the ground, we assume the above steady pressure, $p_{f, o}$, would be the most appropriate value, since it avoids the resistances of rubber sleeve and $\mathrm{CB}$ seal and reflects the pressure required for breaking through the soil mass, as explained previously in the section entitled "Field grouting program". However, this steady pressure would still 
need to be corrected by subtracting the pipe friction as follow:

[1] $p_{f}=p_{f, o}-p_{\text {fric }}$

In accordance, Table 2 indicates the corrected fracturing pressures $\left(p_{f}\right)$ and the associated injection flows $\left(q_{f}\right)$ at various depths of grouting in this field grouting trial.

\section{Hydrofracturing pressure: observations vs. predictions by exiting theories}

A comparison is made between the measured hydrofracturing pressures and the predicted values based on various existing theories. The theory by Andersen et al. (1994) requires additional information of non-linear stress-strain relationship and injection-induced pore pressure of site-specific soils, through finite element analysis and laboratory evaluation, which were not performed in this study. The Andersen approach is therefore not considered and compared with the fracturing pressures measured in the field trial.

Table 3 indicates the measured hydrofracturing pressures fall between the lower limiting values defined by Vaughan (1971) with $m=1$ (Theory V1 in the table), and the upper limiting values determined by the cavity expansion theory (Massarsch 1978) (Theory C in the table). This situation appears consistent with the findings by Jaworski et al. (1979). However, Vaughan's (197) theory, with $m=1$, underestimates by $60-70 \%$, while the cavity theory by Massarsch (1978) overestimates by $20-70 \%$. The theories of Bjerrum et al. (1972), in the case of either circumferential stress $\left(\sigma^{\prime}{ }_{\theta}\right)$ or radial stress $\left(\sigma_{r}^{\prime}\right)$ being exceeded first (Theories B1 \& B2, respectively, in the table), result in similar 
predictions, which underestimate by $20-45 \%$. The Vaughan (1971) theory with $m=2$ (Theory V2 in the table) gives the same range of estimates as the previous two theories by Bjerrum et al. (1972). The predictions by the theory of Bjerrum et al. (1972), in the case of overburden pressure $\left(\sigma^{\prime}{ }_{v}\right)$ being exceeded first (Theory B3 in the table), underestimate by approximately 50\%. The above evaluation indicates all of the existing theories considered herein, except for the cavity expansion theory by Massarsch (1978), tend to underestimate the hydrofracturing pressures in soils as measured in this field trial.

\section{Numerical simulation program}

Numerical simulations are conducted to provide more insights on the hydraulic fracturing in soils. A discrete element method (DEM) is chosen since the method is capable of analyzing interacting deformable bodies undergoing large absolute or relative motions, and is able to model granular materials which may freely make and break contacts with their neighbors (Sitharam 2000). A particle flow code, $\mathrm{PFC}^{2 \mathrm{D}}$, based on DEM, is therefore selected for the numerical computations.

Details of the computation methodology can be found in the code manual (Itasca 2004). Two aspects are worthwhile mentioned herein, in view of the particulate nature of soils and the interaction between injection fluid and soil particles for the hydrofracturing problem in soils. As shown in Fig. 5(a), the bond models, as adopted in $\mathrm{PFC}^{2 \mathrm{D}}$ for defining the relationships among particles, includes 
the contact-bond model and the parallel-bond model. The contact-bond model transmits only normal and shear forces at the contact point of particles, while the parallel-bond model transmits normal and shear forces, as well as the moment in a finite area around the contact point. In considering the particulate nature of soil grains without significant adhesive among them, like rocks, we thus adopt the contact-bond model for the numerical soils in our simulations.

As shown in Fig. 5(b), the injection fluid is assumed as a pressure in $\mathrm{PFC}^{2 \mathrm{D}}$ that exists in a flow domain formed by a closed ring of particles. Fluid flow or pressure may be transmitted among flow domains through the domain connections or "pipes". Depending on domain pressure difference and pipe aperture, the fluid flow through domain pipes are computed based on Darcy's law. In accordance, the changes in volume and fluid pressure for each of the flow domains can be estimated. Given the new domain pressures, the fluid forces exerted on the particles are calculated. The above steps constitute a cycle for the fluid flow computation. With an updated set of forces acting on the particles, a cycle for the mechanical computation can be initiated. At the end of the mechanical computations, the geometry of particle assembly as well as the particle bonding conditions will be revised. The code will subsequently exercise a "domain scan" to redefine the flow domain boundaries and to recalculate the flow pressures within the domains. Afterwards, a new cycle for the fluid flow computation can therefore be restarted. Through the above fluid-mechanical coupling process, the hydraulic fracturing in the numerical soils is simulated accordingly in this study.

As shown in Fig. 6(a), the numerical model consists of a dry particle assembly with a total 
number of approximately 9500 uniform circular discs. The particles are generated within the $1 \mathrm{~m} \times$

$1 \mathrm{~m}$ area restrained by four walls. Confining stresses are then applied through the walls, followed by the creation of a grout hole $(10 \mathrm{~cm}$ in diameter) in the center and the application of injection pressure in the grout hole. During the injection process, displacements of individual particles and penetrations of fluid pressure in pore spaces are computed and recorded. In order to examine the development of stresses in particle assembly during the injection process, a network of measurement circles (MC) is assumed as shown in Fig. 6(b), with each measurement circle containing approximately 20 30 particles. The code, $\mathrm{PFC}^{2 \mathrm{D}}$, allows the computation of average stresses for particles in a measurement circle. With special interests, we select four MCs (\#127, \#130,\#159, and \#98) located close to the left, right, top, and bottom borders of the grout hole, respectively, for the calculation of stress paths in these areas during the injection.

In order to determine the failure boundaries for the stress paths, we conduct a series of plane strain tests (both in compression and extension) by $\mathrm{PFC}^{2 \mathrm{D}}$ to evaluate the shear strength characteristics and tensile strength of the numerical soils. By considering equivalent behaviors between the numerical and the real soils, we select two types of soil samples (CL \& SM1) from the field site with known laboratory strength data as our targets for the calibration. The calibration procedure, similar to those indicated by Wang et al. (2014), involves a systematic adjustment of the micro-parameters (e.g., particle friction coefficient, normal and shear stiffnesses, normal and shear contact bonds, etc.) such that the macro-parameters (i.e., cohesion, friction angle, and tensile strength) of the numerical soils 
are equivalent to those of the in-situ soils (Chang et al. 2009). Fig. 7 shows examples of the numerical samples failed by tension and compression, as well as the calibrated compressive and tensile failure envelops ( $K_{f}$-lines) for the numerical clay and sand. Table 4 summarizes the parameters and properties adopted in the numerical simulations. As seen, the numerical clay is calibrated with a set of macro-parameters: $c=27.4 \mathrm{kPa}, \phi=22.6^{\circ}, \sigma_{t}=5.1 \mathrm{kPa}$; and the numerical sand with the parameters: $c=0, \phi=40.6^{\circ}, \sigma_{t}=0$, which are consistent with the parameters evaluated in laboratory for the in-situ CL and SM1 soils.

\section{Results of numerical simulations}

\section{Effect of soil type on injection mechanism}

Numerical simulations are performed to examine the effect of soil type on the injection mechanism, and results are shown in Fig. 8. Differences in the soil type are due mainly to the micro-parameters assigned for the numerical clay and sand, which are indicated in Table 4. As depicted in the figure, the numerical sand presents slightly more displacements (or compactions) of particles in the vicinity of the injection hole, compared with those of the numerical clay. In terms of fluid pressure penetration, however, the numerical sand shows a much higher pressure penetration (or permeation) into the pore space of particles around the injection hole than that of the numerical clay, which appears in relation to the high permeability of the numerical sand (Table 4). The above simu- 
lations clearly demonstrate the sandy soils would exhibit a more permeation type of injection mech-

anism than for the clayey soils.

\section{Effect of confining stress and stress anisotropy on fracture development}

The effect of confining stress and stress anisotropy is examined for the numerical clay in three cases, all with the same applied injection pressure $\left(p_{\text {inj }}\right)$ of $350 \mathrm{kPa}$. Fig. 9(a) shows the clay is isotropically consolidated by the confining stresses $\sigma_{x}=\sigma_{y}=100 \mathrm{kPa}$, with an average confining stress $\left(\sigma_{\text {ave }}\right)$ of $100 \mathrm{kPa}$ and a stress anisotropy $\left(\sigma_{y} / \sigma_{x}\right)$ of 1.0. Fig. 9(b) shows the clay is also isotropically consolidated but with different confining stresses $\sigma_{x}=\sigma_{y}=65 \mathrm{kPa}$. The average confining stress $\left(\sigma_{\text {ave }}\right)$ of this case is $65 \mathrm{kPa}$ and the stress anisotropy $\left(\sigma_{y} / \sigma_{x}\right)$ is 1.0. Fig. 9(c) shows the clay is anisotropically consolidated with the confining stresses $\sigma_{x}=65 \mathrm{kPa}$ and $\sigma_{y}=130 \mathrm{kPa}$.

The average confining stress $\left(\sigma_{\text {ave }}\right)$ is $97.5 \mathrm{kPa}$, similar to that of the first case (100 kPa; Fig. 9(a)), but the stress anisotropy $\left(\sigma_{y} / \sigma_{x}\right)$ is 2.0 , different from that of the first case which is isotropically consolidated $\left(\sigma_{y} / \sigma_{x}=1.0\right)$.

As illustrated in Fig. 9(a) for the case of higher isotropic stresses $\left(\sigma_{a v e}=100 \mathrm{kPa} ; \sigma_{y} / \sigma_{x}=1\right)$, the injection pressure displaces the clay particles very slightly around the injection hole up to a time step of about 6000 , and then the situation becomes stabilized afterwards with no further compaction or shearing. For the case of lower isotropic stresses $\left(\sigma_{a v e}=65 \mathrm{kPa} ; \sigma_{y} / \sigma_{x}=1\right)$ as shown in Fig. 9(b), however, the injection pressure apparently displaces and compacts the particles around the in- 
jection hole at the time step of 5510. The situation becomes severe at the time step of 11010 and results in more compaction and shearing (or fracturing) of particles proximate to the injection hole, an indication of initiation of hydraulic fracturing.

For the case of anisotropic confining stresses shown in Fig. 9(c) $\left(\sigma_{a v e}=97.5 \mathrm{kPa} ; \sigma_{y} / \sigma_{x}=2\right)$, the pattern of particle displacements indicates the compaction and shearing are even more serious than for the previous case in Fig. 9(b). Displacements of particles promote compaction and shearing (or fracturing) around the injection hole at the time step of 5510 and serious shearing and fracturing at the time step of 11010 .

The dramatic differences in particle movements among the above three cases are in close relation to the magnitude and the anisotropy of the applied confining stresses. In these cases, a confining stress $\left(\sigma_{x}=\sigma_{\text {min }}\right)$ of $65 \mathrm{kPa}$ is considerably lower than the applied injection pressure $\left(p_{\text {inj }}\right)$ of 350 $\mathrm{kPa}$, which would not be sufficient for the confinement and would eventually lead to a fracturing in particle assembly by the injection. In addition, an increase of the confining stress anisotropy $\left(\sigma_{y} / \sigma_{x}\right)$ from 1 to 2 would enhance and accelerate the fracturing process.

The deformation of materials subjected to an injected pressure depends on their strengths and stiffnesses and can behave differently (Bruno et al. 2001). For rock materials, the injection generally results in a brittle type of fracturing with less or negligible deformations (Wang et al. 2009; Shimizu et al. 2011). For soil materials, however, the injection normally leads to more deformations in soils before further shearing or fracturing, as evidenced in laboratory testing (Hou and Bai 1991; Chang 
2004). Based on current numerical simulations, we observe sufficient compaction and shearing (i.e., punching shear) would be necessary prior to the fracturing (i.e., parting or splitting) in numerical soils due to the injection, which is consistent with the findings in the literature.

In the numerical simulations herein, we notice the development of shearing and fracturing are in the direction of maximum confining stress (i.e., major principal stress) or the plane upon which the minimum confining stress (i.e., minor principal stress) acts, which is also in agreement with the literature (Yanagisawa and Panah 1994; Chang 2004; Wang et al. 2009; Shimizu et al. 2011; Nasehi and Mortazavi 2013)

\section{Effective stress paths for soil particles around grout hole during the injection}

In order to understand the stress condition during the process of injection, the stress paths of soil particles in the vicinity of injection hole are computed for both the numerical clay and sand, using the material data shown in Table 4. The simulations are conducted in an anisotropic stress condition $\left(\sigma_{x}=\sigma_{x}^{\prime}=65 \mathrm{kPa}\right.$ and $\left.\sigma_{y}=\sigma_{y}^{\prime}=130 \mathrm{kPa}\right)$ with the injection pressure $p_{i n j}=350 \mathrm{kPa}$. As stated previously, four measurement circles (MC\#159, MC\#98, MC\#127, and MC\#130; Fig. 6(b)) near the top, bottom, left, and right borders of the injection hole, respectively, are selected for computing the stresses of particles in the measurement circles. All stress paths start at the same stress point with $p^{\prime}=\left(\sigma^{\prime}{ }_{y}+\sigma^{\prime}{ }_{x}\right) / 2=97.5 \mathrm{kPa}$ and $q^{\prime}=\left({\sigma^{\prime}}_{y}-\sigma^{\prime}{ }_{x}\right) / 2=32.5 \mathrm{kPa}$, representing the stress condition in numerical soils prior to the excavation of injection hole. The injection hole is then 
excavated with the injection pressure applied. The stresses of particles in the above measurement circles are computed until a time step of 6000 .

Due to small size of measurement circles (with each contained 20 30 particles initially) as well as movements of particles during injection, the number of particles in the measurement circles would likely vary and thus affect the stress computation. In accordance, the computed stress paths, as shown in Fig. 10, exhibit a somewhat erratic phenomenon. The general trend of stress development, however, would not be altered and can still be used for the interpretation of behavior of particle assembly during the injection.

Fig. 10(a) shows computed stress paths for the numerical clay in the process of injection. The stress paths for the particles at top and bottom borders of the injection hole (MC\#159 and MC\#98) generally move right and upwards and then touch the shear failure boundary defined by Mohr-Coulomb theory. Alternatively, the stress paths of the particles at left and right borders of the injection hole (MC\#127 and MC\#130) move right but downwards, without reaching the shear failure boundary. Accordingly, the particles at top and bottom borders of the injection hole fail in shear during the injection, while the particles at left and right borders remain intact.

We notice the stress paths of particles in MC\#159 and MC\#98 are redirected to lower stress values away from the failure boundary after shear failure has occurred. This situation appears in relation to the significant deformations at the top and bottom of the injection hole due to the shear failure in clay of these areas. The expanded injection hole intersects the assigned measurement circles 
(MC\#159 and MC\#98) and thus reduces substantially the number of particles in the measurement circles for stress computation. In accordance, the computed stresses are reduced and the stress paths are redirected to lower stress states.

Figs. 10(b) \& (c) also show the particle assembly with fluid pressure penetration as well as the displacement contours of particles at a time step of 6000 . Obviously, the injection has resulted in a punching shear type of fracturing in the direction of major principal stress for the numerical clay under anisotropic stress condition. This result is consistent with the findings in previous literature (Panah and Yanagisawa 1989; Hou and Bai 1991; Alsiny et al. 1992; Chang 2004; Kim 2005).

Fig. 11(a) shows the computed stress paths for numerical sand during the injection. Initially, the stress paths of the particles at top and bottom borders of the injection hole move right and upwards, and the stress paths of the particles at left and right borders move right and downwards, a similar situation as found for the numerical clay. However, all of the stress paths switch to the left in about the midway of injection, and finally touch the Mohr-Coulomb failure lines. Due to high permeability of the numerical sand, the injected pressure easily penetrates into the pore spaces of particles around the injection hole, as evidenced in Fig. 11(b). In accordance, the effective stresses in particles around the injection hole would be reduced owing to the injected excess pore pressure, resulting in a switch-back in the effective stress paths.

Based on the computed displacement contours of particles (Fig. 11(c)), the excess pore pressure promotes more displacements (i.e., compressions and shears) in particles at the top and bottom bor- 
ders of the injection hole, as a result of the anisotropic stress condition in this case. The liquefaction-like of fracturing, as observed in the current simulations and previous literature (Sitharam 2000; Chang 2004; Shimizu et al. 2011), appears to be a unique mode for fracture initiation in the sandy soils with high permeability.

\section{Proposed mode and pressure estimation for hydraulic fracturing in soils}

Both field observations and numerical simulations conducted in this study suggest the soils proximate to the injection hole require considerable compressions and shears prior to the fracturing.

This situation apparently differs from the hydraulic fracturing in rocks, which normally exhibit a more splitting type of fracturing, i.e., a tensile mode of fracturing. Accordingly, a "punching and splitting mode" is proposed herein for the hydraulic fracturing in soils. As depicted in Fig. 12(a), the application of injection pressure $p_{f}$ results in a punching (shear) with the formation of a failure wedge adjacent to a borehole and a subsequent splitting of the soil mass in front of the wedge. This punching and splitting type of fracturing would be initiated and propagated in soil mass where the resistance is the least, i.e., in a direction parallel to the major principal stress or the plane upon which the minor principal stress acts.

In order to estimate the pressure required for fracturing based on the proposed mode, we make the following assumptions: (1) no stress redistribution in soil mass due to the application of injection 
pressure; (2) no liquefaction-like of fracturing as a result of injected pressure in to the pores of soil grains. A punching shear is a passive type of failure in soils, which can be estimated by Rankine's earth pressure theory. However, the punching failure of soils proximate to the injection hole is different from the passive failure in a retaining structure. As shown in Figs. 12(b) \& (c), the failure wedge in a retaining structure allows for a transverse movement when the ultimate passive pressure is applied, while the failure wedge proximate to an underground open space or a borehole is limited by the movement and requires a separation (or splitting) of soil mass in front of the wedge due to the kinematic restraints.

Depending on the rigidity of soil mass, the pressure required for forming a punching wedge and a splitting in the soil mass ahead due to the injection would appear to fall in a pressure range defined by the following two types. Type I of the proposed mode concerns a brittle material in which the fracturing pressure $\left(p_{f}\right)$ can be estimated based on Rankine's passive theory:

[2a] $p_{f}=K_{p}^{\prime} \sigma_{\text {min }}^{\prime}+2 c^{\prime} K_{p}^{\prime 0.5}+u_{w}$ or

[2b] $p_{f}=K_{p} \sigma_{\min }+2 c K_{p}^{0.5}$

in terms of effective or total stress, respectively. In the above equations, $K_{p}^{\prime}=\tan ^{2}\left(45^{\circ}+\phi^{\prime} / 2\right)$ and $K_{p}=\tan ^{2}\left(45^{\circ}+\phi / 2\right)$ are the coefficients of Rankine's passive earth pressure in terms of effective and total stresses, $c^{\prime}-\phi^{\prime}$ and $c-\phi$ are the effective and total strength parameters of soil, and $u_{w}$ is the static pore water pressure in soil. Type II of the proposed mode considers a ductile material where the above Rankine pressures would not suffice and requires an additional pressure, 
$\Delta p_{f}=\sigma_{\min }+\sigma_{t}$, for jacking up the soil mass in front of the failure wedge. The fracturing pressure for this type is therefore in the form:

[3a] $p_{f}=\left(K_{p}^{\prime}+1\right) \sigma_{\text {min }}^{\prime}+2 c^{\prime} K_{p}^{\prime 0.5}+2 u_{w}+\sigma_{t}$ or

[3b] $p_{f}=\left(K_{p}+1\right) \sigma_{\min }+2 c K_{p}^{0.5}+\sigma_{t}$

in terms of effective or total stress, respectively, and where $\sigma_{t}$ is the tensile strength of soil in total stress. For sandy soils, however, the tensile strength of these materials would likely be small and can be neglected.

The above relationships of fracturing pressure based on the proposed mode are verified with cases of field testing and numerical simulations of this study, and results are indicated in Table 5. Apparently, Type II relationship provides more accurate predictions of fracturing pressures measured in the field with errors less than about $\pm 10 \%$, while Type I underestimates the predictions with errors up to $30-35 \%$. For the numerical simulation cases, Type II relationship also shows better predictions over those by Type I relationship. In accordance, the relationship depicted by eq. [3a] or [3b] appears more appropriate for estimation of the hydrofracturing pressure in soil materials.

The proposed mode and pressure estimation of hydraulic fracturing in soils by this study, however, does not consider the liquefaction-like of fracturing, which is observed in granular soils by the solution type of injection fluid. The injected fluid pressure would penetrate into the pore space of soil grains, build up pore pressure and thus reduce effective stress and strength of the soil. Consequently, the proposed relationship (eq. [3a] or [3b]) would overestimate the hydrofracturing pressure of this 
kind.

Actual mechanism of fracturing in soils would be very complicated as mentioned by Mitchell and Soga (2005), which may include plastic deformation at the fracture tip, soil rate effect, permeation of injection fluid from fracture into soils, etc. In accordance, the proposed pressure estimation for hydraulic fracturing in soils should be used as preliminary purposes.

\section{Summary and conclusions}

This paper discusses the observations of hydraulic fracturing in soils through field testing and numerical simulations. Major findings of this study are summarized as follows:

1. Hydraulic fracturing in soils is observed in field as predicted by generally accepted penetrability (groutability) requirements based on particle size ratio. Hydraulic fracturing is the primary mechanism of injection in this field grouting trial, however, permeation is also found in sandy layers by the solution grout or a long gel-time suspension grout.

2. Hydraulic fractures in the field are found to be vertically developed and exited to the ground surface, indicating the soil strata at the site are normally consolidated.

3. Measured fracturing pressures in the field fall between a lower limit defined by Vaughan (1971) with $m=1$ and an upper limit based on cavity expansion theory (Massarsch 1978). However, Vaughan's values underestimate by $60-70 \%$, while Massarsch's predictions overestimate by 
$20-70 \%$. Predictions of fracturing pressure in soils by the existing theories show considerable variations with the field measurements.

4. Numerical simulations confirm that the sand would exhibit a more permeation type of mechanism than the clay, mainly due to the permeability properties of the soils.

5. Numerical simulations indicate the hydraulic fracturing in soils is more easily triggered in anisotropic stress conditions, in which the minor principal stress is the key influencing factor. Hydraulic fractures are developed in the direction parallel to the major principal stress or the plane upon which the minor principal stress acts.

6. Numerical simulations demonstrate significant compressions or shears prior to the fracturing in soils, suggesting the fracturing mechanism for soils would be of a shearing type.

7. Based on field observations and numerical simulations, we propose a punching and splitting mode for the hydraulic fracturing in soils, which involves a punching with the formation of a failure wedge and a subsequent splitting of the soil mass in front of the wedge due to the application of injection pressure.

8. A relationship for fracturing pressure estimation based on the proposed mode is established and verified. Generally, good agreements are found between the proposed relationship (eq. [3a] or [3b]) and the results of field and numerical cases of this study.

9. The proposed mode and relationship for fracturing pressure estimation does not consider the liquefaction-like of fracturing, and the use of the proposed relationship (eq. [3a] or [3b]) would 
overestimate the hydrofracturing pressure of this kind.

10. The liquefaction-like of fracturing, resulting from the injection pressure penetration into soil grains causing excess pore pressures and thus reducing effective stresses and strength, would be a unique mode of fracture initiation for the sandy soils with high permeability.

This paper discusses the observations of hydraulic fracturing in soils through field testing and numerical simulations. Major findings of this study are summarized as follows:

\section{Acknowledgements}

This study was financially supported by the Ministry of Science \& Technology, Taiwan (Grant No. NSC94-2815-C-224-011E), the Diffisoil Geotechnical Engineering Co., Taiwan (Grant No. YT94-117), and National Yunlin University of Science \& Technology (NYUST), Taiwan (Grant No. YT96T04). The authors would like to thank the following personnel for carrying out the field work of this study: T.W. Mao, C.C. Chen, and other members of the Geotechnical Engineering Group in NYUST.

\section{References}

Akbulut, S., and Saglamer, A. 2002. Estimating the groutability of granular soils: a new approach. Tunnelling and Underground Space Technology, 17: 371-380.

Alfaro, M.C., and Wong, R.C.K. 2001. Laboratory studies on fracturing of low-permeability soils. Canadian Geotechnical Journal, 38: 303-315.

Alsiny, A., Vardoulakis, I., and Dresher, A. 1992. Deformation localization in cavity inflation experiments on dry sand. Géotechnique, 42(3): 395-410.

Andersen, K.H., Rawlings, C.G., Lunne, T.A., and By, T.H. 1994. Estimation of hydraulic fracture pressure in clay. Canadian Geotechnical Journal, 31: 817-828.

Axelsson, M., Gustafson, G., and Fransson, A. 2009. Stop mechanism for cementitious grouts at different water-to-cement ratios. Tunnelling and Underground Space Technology, 24: 390-397.

Bjerrum, L., Nash, J.K.T.L., Kennard, R.M., and Gibson, R.E. 1972. Hydraulic fracturing in field permeability testing. Géotechnique, 22(2): 319-332.

Bruno, M.S., Dorfmann, A., and Lao, K. 2001. Coupled particle and fluid flow modeling of fracture 
and slurry injection in weakly consolidated granular media. In Proceedings of the 38th US Rock Mech. Sym. (Rock 2001), Washington DC, pp. 421-428.

Chang, H. 2004. Hydraulic Fracturing in Particulate Materials. PhD Dissertation, School of Civil and Environmental Engineering, Georgia Institute of Technology.

Chang, M., Chen, C.C., Huang, R.C., Chang, J., and Yang, P.J. 2009. Investigation on mechanism of grouting and engineering characteristics of in-situ grouted soils. In Proceedings of the 17th Int. Conf. Soil Mech. Geotech. Engrg, Alexandria, Egypt, pp. 2346-2349.

Choi, H.G., and Yanagisawa, E. 1996. Permeation grouting and fracturing in sandy soil. In Grouting and Deep Mixing, Balkema, Rotterdam, pp. 117-122.

Djarwadi, D., Suryolelono, K.B., Suhendro, B., and Hardiyatmo, H.C. 2014. Selection of soils as clay core embankment materials for rock fill dams to resist hydraulic fracturing. Procedia Engineering 95: 489-497.

GeoDelft, 2002. Hydraulic fracturing with distinct element method. CO386730/12, Version 3, GeoDelft, The Netherlands.

Graf, E.D. 1992. Compaction grouting, 1992. In Grouting, soil improvement and geosynthetics. GSP 30, ASCE, pp. 275-287.

Haimson, B. 1968. Hydraulic fracturing in porous and non-porous rock and its potential for determining in-situ stresses at great depth. Technical Report No.4-68, US Army Corps of Engineers, Missouri Division, Omaha, NB, pp. 319-332.

Hausmann, M.R. 1990. Engineering principles of ground modification. McGraw-Hill, Inc.

Hou, X.Y., and Bai, Y. 1991. The mechanism and application of grouting in soft clay. In Proceedings of the 9th Asian Regional Conf. Soil Mech. Found. Engng, Bangkok, Thailand, pp. 487-490.

Itasca, 2004. Particle flow code in 2 dimensions, user's manual. Itasca Consulting Group, Inc.

Jaworski, G.W., Duncan, J.M., and Seed, H.B. 1979. An experiment study of hydraulic fracturing. Geotech. Engng. Report No. UCB/GT/79-02, Dept. of Civil Engng., UC Berkeley.

Jaworski, G.W., Duncan, J.M., and Seed, H.B. 1981. Laboratory study of hydraulic fracturing. Journal of Geotechnical Engineering Division, 107(GT6): 713-732.

Kim, S. 2005. Mechanics of catastrophic failure of soils. PhD Dissertation, School of Civil and Environmental Engineering, Georgia Institute of Technology.

Kravetz, G.A. 1958. Cement and clay grouting of foundations: the use of clay in cement grouts. Journal of Soil Mechanics and Foundation Division, 84(SM1), Proc. Paper 1546: 1-30.

Lo, K.Y., and Kaniaru, K. 1990. Hydraulic fracture in earth and rock-fill dams. Canadian Geotechnical Journal, 27: 496-605.

Massarsch, K.R. 1978. New aspects of soil fracturing in silt-clay. Journal of Geotechnical Engineering Division, 104(GT8): 1109-1123.

Mitchell, J.K. 1982. Soil improvement - state of the art. In Proceedings of the 10th Int. Conf. Soil Mech. Found. Engng., Stockholm, Sweden, pp. 509-566.

Mitchell, J.K., and Soga, K. 2005. Fundamentals of soil behavior. John Wiley and Sons, Inc. 
Mitchell, J.K., and Van Court, W.A. 1992. The role of soil modification in environmental engineering applications. In Grouting, soil improvement and geosynthetics. GSP 30, ASCE, pp. 110-143.

Morgenstern, N.R., and Vaughan, P.R. 1963. Some observations on allowable grout pressures. In Proceedings of the Conf. on Grouts \& Drilling Muds, London, England.

Mori, A., and Tamura, M. 1987. Hydrofracturing pressure of cohesive soils. Soils and Foundations, 27(1): 14-22.

Mori, A., Tamura, M., Shibata, H., and Hayashi, H. 1992. Some factors related to injected shape in grouting. In Grouting, soil improvement and geosynthetics. GSP 30, ASCE, pp. 313-324.

Murdoch, L.C., and Slack, W.W. 2002. Forms of hydraulic fractures in shallow fine-grained formations. Journal of Geotechnical and Geoenvironmental Engineering, 128(6): 479-487.

Nasehi, M.J., and Mortazavi, A. 2013. Effect of in-situ stress regime and intact rock strength parameters on the hydraulic fracturing. Journal of Petroleum Science and Engineering, 108: 211-221.

Panah, A.K., and Yanagisawa, E. 1989. Laboratory studies on hydraulic fracturing criteria in soil. Soils and Foundations, 29(4): 14-22.

Sherard, J.L. 1985. Hydraulic fracturing in embankment dams. Journal of Geotechnical and Geoenvironmental Engineering, 112(10): 905-927.

Shimizu, H., Murata, S., and Ishida, T. 2011. The distinct element analysis for hydraulic fracturing in hard rock considering fluid viscosity and particle size distribution. Int. J. Rock Mech. Mining Sci., 48: $712-727$.

Sitharam, T.G. 2000. Numerical simulation of particulate materials using discrete element modeling. Current Science, 78(7): 876-886.

Vaughan, P.R. 1971. The use of hydraulic fracturing tests to detect crack formation in embankment dam cores. Interim Report, Dept. Civil Engng., Imperial College, Landon, England.

Vesic, A.S. 1972. Expansion of cavities in infinite soil mass. Journal of Soil Mechanics and Foundation Division, 98(3): 265-290.

Wang, S.Y., Sun, L., Au, A.S.K., Yang, T.H., and Tang, C.A. 2009. 2D-numerical analysis of hydraulic fracturing in heterogeneous geo-materials. Construction and Building Materials, 23: 2196-2206.

Wang, T., Zhou, W., Chen, J. Xiao, X., Li, Y., and Zhao, X. 2014. Simulation of hydraulic fracturing using particle flow method and application in a coal mine. International Journal of Coal Geology, 121: $1-13$.

Warner, J. 1992. Compaction grout; rheology vs. effectiveness. In Grouting, soil improvement and geosynthetics. GSP 30, ASCE, pp. 229-239.

Whittaker, B.N., Singh, R.N., and Sun, G. 1992. Rock fracture mechanics - principles, design and applications. Amsterdam, Elsevier.

Wong, R.C.K., and Alfaro, M.C. 2001. Fracturing in low-permeability soils for remediation of contaminated ground. Canadian Geotechnical Journal, 38: 316-327.

Yanagisawa, E., and Panah, A.K. 1994. Two dimensional study of hydraulic fracturing criteria in co- 
hesive soils. Soils and Foundations, 34(1): 1-9.

Yokoyama, T., Sano, O., Hirata, A., Ogawa, K., Nakayama, Y., Ishida, T., and Mizuta, Y. 2014. Development of borehole-jack fracturing technique for in situ stress measurement. Int. J. Rock Mech. Mining Sci., 67: 9-19. 


\section{Table Captions:}

Table 1. Adopted grouts, onsite soils, and observed injection mechanisms.

Table 2. Observed hydraulic fracturing pressures at representative grouting depths.

Table 3. Comparison of observed and theoretical hydrofracturing pressures.

Table 4. Parameters or properties adopted in numerical simulations.

Table 5. Verifications of fracturing pressures based on the proposed mode of hydraulic fracturing. 


\section{Figure Captions:}

Fig. 1. Site plan and soil profile.

Fig. 2. Soil grouting by tube-á-manchette (TAM).

Fig. 3. Observations of grout emergence on the ground surface and grout traces in each of the excavation stages.

Fig. 4. Injection pressure vs. injection rate relationship at Grouting Depth $7.41 \mathrm{~m}$ (Injection Point \#10).

Fig. 5. Bonding logic and fluid flow domain structure in $\mathrm{PFC}^{2 \mathrm{D}}$.

Fig. 6. Numerical model for simulation of grouting in soil.

Fig. 7. Numerical simulations of plane strain compressive and tensile tests for dry soils.

Fig. 8. Numerical grouting in clayey and sandy soils $\left(\sigma_{x}=\sigma_{y}=100 \mathrm{kPa}, p_{i n j}=350 \mathrm{kPa}, T S=6000\right)$.

Fig. 9. Effect of confining stress and stress anisotropy on grouting mechanism in clay $\left(p_{\text {inj }}=350 \mathrm{kPa}\right)$.

Fig. 10. Results of numerical grouting in clay $\left(p_{i n j}=350 \mathrm{kPa}, \sigma_{x}=65 \mathrm{kPa}, \sigma_{y}=130 \mathrm{kPa}\right)$.

Fig. 11. Results of numerical grouting in sand ( $\left.p_{i n j}=350 \mathrm{kPa}, \sigma_{x}=65 \mathrm{kPa}, \sigma_{y}=130 \mathrm{kPa}\right)$.

Fig. 12. Proposed injection mechanism of the hydraulic fracturing in soils. 


\section{Table Captions:}

Table 1. Adopted grouts, onsite soils, and observed injection mechanisms.

Table 2. Observed hydraulic fracturing pressures at representative grouting depths.

Table 3. Comparison of observed and theoretical hydrofracturing pressures.

Table 4. Parameters or properties adopted in numerical simulations.

Table 5. Verifications of fracturing pressures based on the proposed mode of hydraulic fracturing. 
Table 1. Adopted grouts, onsite soils, and observed injection mechanisms.

\begin{tabular}{|c|c|c|c|c|c|c|c|}
\hline $\begin{array}{l}\text { Grout name } \\
\& \text { type }\end{array}$ & $\begin{array}{l}\text { Major } \\
\text { components }^{a}\end{array}$ & $\begin{array}{l}D_{85}^{\text {grout }} \\
(\mathrm{mm})\end{array}$ & $\begin{array}{l}\text { Depths } \\
\text { applied } \\
(\mathrm{m})\end{array}$ & $\begin{array}{l}\text { Soil type } \\
\text { encountered }\end{array}$ & $\begin{array}{l}D_{15}^{\text {soil }} \\
(\mathrm{mm})\end{array}$ & $\frac{D_{15}^{\text {soil }}}{D_{85}^{\text {grout }}}$ & $\begin{array}{l}\text { Observed } \\
\text { mechanism }\end{array}$ \\
\hline $\begin{array}{l}\text { GCB } \\
\text { suspension }\end{array}$ & $\begin{array}{l}\text { Sodium silicate (12.2), } \\
\text { Cement (8.0), } \\
\text { Bentonite (1.0), } \\
\text { Water (33.6) }\end{array}$ & 0.033 & $\begin{array}{l}4.2 \sim 5.1 \\
5.1 \sim 6.0 \\
6.0 \sim 6.2\end{array}$ & $\begin{array}{l}\text { CL } \\
\text { SM1 } \\
\text { SM2 }\end{array}$ & $\begin{array}{l}0.0004 \\
0.0200 \\
0.0080\end{array}$ & $\begin{array}{l}<0.1 \\
0.6 \\
0.2\end{array}$ & $\begin{array}{l}\text { Fracturing }(*) \\
\text { Compaction }\end{array}$ \\
\hline $\begin{array}{l}\mathrm{CB} \\
\text { suspension }\end{array}$ & $\begin{array}{l}\text { Cement (8.0), } \\
\text { Bentonite (1.0), } \\
\text { Water (20.0) }\end{array}$ & 0.033 & $\begin{array}{l}6.2 \sim 6.6 \\
6.6 \sim 7.0 \\
7.0 \sim 7.2\end{array}$ & $\begin{array}{l}\mathrm{SM} 2 \\
\mathrm{ML} \\
\mathrm{SM} 2\end{array}$ & $\begin{array}{l}0.0080 \\
-_{c} \\
0.0060\end{array}$ & $\begin{array}{l}0.2 \\
-c \\
0.2\end{array}$ & $\begin{array}{l}\text { Fracturing }(*) \\
\text { Permeation }\end{array}$ \\
\hline $\begin{array}{l}\text { SA40 } \\
\text { solution }\end{array}$ & $\begin{array}{l}\text { Sodium silicate (8.0), } \\
\text { SA40 (1.0), } \\
\text { Water (31.0) }\end{array}$ & $\mathrm{N} / \mathrm{A}^{b}$ & $\begin{array}{l}7.2 \sim 7.6 \\
7.6 \sim 8.2\end{array}$ & $\begin{array}{l}\mathrm{SM} 2 \\
\mathrm{ML}\end{array}$ & $\begin{array}{l}0.0060 \\
-^{c}\end{array}$ & $\begin{array}{l}\mathrm{N} / \mathrm{A}^{b} \\
-{ }^{c}\end{array}$ & $\begin{array}{l}\text { Permeation }(*) \\
\text { Fracturing }(*)\end{array}$ \\
\hline
\end{tabular}


Table 2. Observed hydraulic fracturing pressures at representative grouting depths.

\begin{tabular}{|c|c|c|c|c|c|c|c|c|}
\hline \multirow[b]{2}{*}{$\begin{array}{l}\text { Grouting } \\
\text { stage }\end{array}$} & \multirow{2}{*}{$\begin{array}{l}\text { Grouting } \\
\text { depths } \\
(\mathrm{m})\end{array}$} & \multirow[b]{2}{*}{ Soil type } & \multirow[b]{2}{*}{ Grout type } & \multicolumn{2}{|c|}{ Hydraulic fracturing } & \multicolumn{3}{|c|}{$\begin{array}{l}\text { Pressure terms defined in } \\
\text { Fig. } 4\end{array}$} \\
\hline & & & & $\begin{array}{l}\text { Pressures } \\
p_{f}{ }^{a}(\mathrm{kPa})\end{array}$ & $\begin{array}{l}\text { Grout flows } \\
q_{f}(\mathrm{~L} / \mathrm{min})\end{array}$ & $\begin{array}{l}p_{b, 0} \\
(\mathrm{kPa})\end{array}$ & $\begin{array}{l}p_{f, 0} \\
(\mathrm{kPa})\end{array}$ & $\begin{array}{l}p_{\text {fric }} \\
(\mathrm{kPa})\end{array}$ \\
\hline I-A & 4.74 & Silty clay (CL) & $\begin{array}{l}\text { GCB } \\
\text { (suspension) }\end{array}$ & $\sim 150$ & $\sim 6.96$ & $\sim 189$ & $\sim 156$ & $\sim 6$ \\
\hline $\mathrm{I}-\mathrm{B}$ & 5.74 & $\begin{array}{l}\text { Silty sand } \\
\quad \text { - coarser (SM1) }\end{array}$ & $\begin{array}{l}\text { GCB } \\
\text { (suspension) }\end{array}$ & $200 \sim 250$ & $1.81 \sim 2.74$ & $\begin{array}{l}283 \\
\sim 1002\end{array}$ & $\begin{array}{l}201 \\
\sim 251\end{array}$ & $\sim 1$ \\
\hline II & 6.74 & $\begin{array}{l}\text { Silty sand } \\
\quad \text { - finer (SM2) } \\
\sim \text { Sandy silt (ML) }\end{array}$ & $\begin{array}{l}\text { CB } \\
\text { (suspension) }\end{array}$ & $220 \sim 230$ & $2.55 \sim 4.10$ & $\begin{array}{l}433 \\
\sim 987\end{array}$ & $\begin{array}{l}339 \\
\sim 349\end{array}$ & $\sim 119$ \\
\hline III & 8.07 & Sandy silt (ML) & $\begin{array}{l}\text { SA40 } \\
\text { (solution) }\end{array}$ & $\sim 270$ & $\sim 6.14$ & $\sim 359$ & $\sim 270$ & $\sim 0$ \\
\hline
\end{tabular}

${ }^{a}$ The fracturing pressures are corrected by subtracting the frictions in grout pipe (i.e., $p_{\text {fric }}$ ) during the grouting. 
Table 3. Comparison of observed and theoretical hydrofracturing pressures.

\begin{tabular}{|c|c|c|c|c|c|c|c|c|c|}
\hline \multirow{2}{*}{$\begin{array}{l}\text { Grouting } \\
\text { stage / } \\
\text { depth } \\
\text { (m) }\end{array}$} & \multirow{2}{*}{$\begin{array}{l}\text { Major } \\
\text { soil } \\
\text { type }\end{array}$} & \multirow{2}{*}{$\begin{array}{l}\text { Material data } \\
c^{\prime} / \phi^{\prime} / \sigma_{t} \\
\left(\mathrm{kPa} /{ }^{\mathrm{o}} / \mathrm{kPa}\right)\end{array}$} & \multicolumn{7}{|c|}{$\begin{array}{l}\text { Observed \& computed hydrofracturing pressures, } p_{f}(\mathrm{kPa}) \text {, and [errors] with re- } \\
\text { spect to the observed pressure }\end{array}$} \\
\hline & & & $\begin{array}{l}\text { Observed } \\
p_{f}\end{array}$ & $\begin{array}{l}\text { Theory } \\
\text { V1 }{ }^{b}\end{array}$ & $\begin{array}{l}\text { Theory } \\
\mathrm{V} 2^{c}\end{array}$ & $\begin{array}{l}\text { Theory } \\
\text { B1 }{ }^{d}\end{array}$ & $\begin{array}{l}\text { Theory } \\
\mathrm{B} 2^{e}\end{array}$ & $\begin{array}{l}\text { Theory } \\
\text { B3 }^{f}\end{array}$ & $\begin{array}{l}\text { Theory } \\
\mathrm{C}^{g}\end{array}$ \\
\hline I-A / 4.74 & $\mathrm{CL}$ & $0 / 30.5 / 5$ & $\sim 150$ & $\begin{array}{l}58 \\
{[-61 \%]}\end{array}$ & $\begin{array}{l}111 \\
{[-26 \%]}\end{array}$ & $\begin{array}{l}91 \sim 103 \\
{[-39 \% \sim-31 \%]}\end{array}$ & $\begin{array}{l}97 \sim 112 \\
{[-35 \% \sim-25 \%]}\end{array}$ & $\begin{array}{l}81 \\
{[-46 \%]}\end{array}$ & $\begin{array}{l}215 \\
{[+43 \%]}\end{array}$ \\
\hline I-B / 5.74 & SM1 & $0 / 39.9 / 0$ & $\sim 200$ & $\begin{array}{l}58 \\
{[-71 \%]}\end{array}$ & $\begin{array}{l}117 \\
{[-42 \%]}\end{array}$ & $\begin{array}{l}128 \sim 162 \\
{[-36 \% \sim-19 \%]}\end{array}$ & $\begin{array}{l}116 \sim 145 \\
{[-42 \% \sim-28 \%]}\end{array}$ & $\begin{array}{l}99 \\
{[-51 \%]}\end{array}$ & $\begin{array}{l}342 \\
{[+71 \%]}\end{array}$ \\
\hline II / 6.74 & $\begin{array}{l}\mathrm{SM} 2 \sim \\
\mathrm{ML}\end{array}$ & $0 / 26.5 / 0$ & $\sim 225$ & $\begin{array}{l}85 \\
{[-62 \%]}\end{array}$ & $\begin{array}{l}170 \\
{[-24 \%]}\end{array}$ & $\begin{array}{l}124 \sim 147 \\
{[-45 \% \sim-35 \%]}\end{array}$ & $\begin{array}{l}128 \sim 152 \\
{[-43 \% \sim-32 \%]}\end{array}$ & $\begin{array}{l}117 \\
{[-48 \%]}\end{array}$ & $\begin{array}{l}273 \\
{[+21 \%]}\end{array}$ \\
\hline III / 8.07 & ML & $0 / 30 / 0$ & $\sim 270$ & $\begin{array}{l}100 \\
{[-63 \%]}\end{array}$ & $\begin{array}{l}200 \\
{[-26 \%]}\end{array}$ & $\begin{array}{l}164 \sim 188 \\
{[-39 \% \sim-30 \%]}\end{array}$ & $\begin{array}{l}169 \sim 194 \\
{[-37 \% \sim-28 \%]}\end{array}$ & $\begin{array}{l}141 \\
{[-48 \%]}\end{array}$ & $\begin{array}{l}372 \\
{[+37 \%]}\end{array}$ \\
\hline
\end{tabular}

${ }^{a}$ Effective shear strength parameters are evaluated based on laboratory tests of the onsite soils. Tensile strengths $\left(\sigma_{t}\right)$ for cohesive soils are assumed to be one-tenth of the undrained shear strength of the soils.

${ }^{b}$ Based on Haimson (1968), Vaughan (1971) and Jaworski et al. (1981), the fracturing pressure can be expressed as: $p_{f}=m \sigma_{m i n}+\sigma_{t}$, with $m=1$.

$c$ Same as the above, except for $m=2$.

${ }^{d}$ Based on Bjerrum et al. (1972), the fracturing pressure can be expressed as: $p_{f}=(1 / v-1)\left[(1-\alpha) \sigma^{\prime}{ }_{h 0}+\sigma_{t}\right]+u_{0}$, for the case where the circumferential stress $\sigma_{\theta}^{\prime}$ adjacent to borehole is exceeded. The coefficient $\alpha$ varied from 0.4 to -1.1 , depending on the hardness of soils.

$e$ Same sources as the above, the fracturing pressure can be expressed as: $p_{f}=(1-v)\left[(2+\beta-\alpha) \sigma^{\prime}{ }_{h 0}+\sigma_{t}\right]+u_{0}$, for the case where the radial stress $\sigma_{r}^{\prime}$ adjacent to borehole is exceeded. The coefficient $\beta$ varied from 0.5 to 4.2 , depending on the hardness of soils.

$f$ Same sources as the above, the fracturing pressure can be expressed as: $p_{f}=\sigma_{v 0}$, for the case where the total vertical stress $\sigma_{v 0}$ is exceeded.

$g$ Based on the cavity expansion theory (Massarsch 1978), the fracturing pressure can be expressed as: $p_{u}=\tau_{f} l n\left(1.36 E / \tau_{f}(1+v)\right)$. 
Table 4. Parameters or properties adopted in numerical simulations.

\begin{tabular}{|c|c|c|}
\hline Parameter / property & Clay & Sand \\
\hline Total number of particles (approximately) & 9500 & 9500 \\
\hline Maximum particle radius, $r_{\max }(\mathrm{mm})$ & 5 & 5 \\
\hline Minimum particle radius, $r_{\min }(\mathrm{mm})$ & 4 & 4 \\
\hline Porosity of particle assembly, $n$ & 0.15 & 0.15 \\
\hline Density of particle, $\rho_{s}\left(\mathrm{~kg} / \mathrm{m}^{3}\right)$ & 2000 & 2000 \\
\hline Density of particle assembly, $\rho\left(\mathrm{kg} / \mathrm{m}^{3}\right)$ & 1700 & 1700 \\
\hline Model width, $W(\mathrm{~mm})$ & 1000 & 1000 \\
\hline Model height, $H(\mathrm{~mm})$ & 1000 & 1000 \\
\hline Grout hole diameter, $D(\mathrm{~mm})$ & 100 & 100 \\
\hline Particle friction coefficient, fric & 0.2 & 1.5 \\
\hline Particle normal stiffness, $k_{n}(\mathrm{~N} / \mathrm{m})$ & $8 \mathrm{E} 7$ & $8 \mathrm{E} 7$ \\
\hline Particle shear stiffness, $k_{s}(\mathrm{~N} / \mathrm{m})$ & $4.8 \mathrm{E} 7$ & 4.8E7 \\
\hline Particle contact bond normal force, $n \_b o n d(\mathrm{~N})$ & 200 & 0 \\
\hline Particle contact bond shear force, $s \_$bond $(\mathrm{N})$ & 2000 & 0 \\
\hline Particle assembly permeability, $K_{h}(\mathrm{~m} / \mathrm{sec})$ & $3 \mathrm{E}-10$ & $3 \mathrm{E}-6$ \\
\hline Wall normal stiffness, $k_{n(w)}(\mathrm{N} / \mathrm{m})$ & $1 \mathrm{E} 10$ & $1 \mathrm{E} 10$ \\
\hline Wall shear stiffness, $k_{s(w)}(\mathrm{N} / \mathrm{m})$ & 0 & 0 \\
\hline Fluid injection pressure, $p_{\text {in } i}(\mathrm{kPa})$ & 350 & 350 \\
\hline Fluid bulk modulus, $B_{f}(\mathrm{kPa})$ & $1 \mathrm{E} 6$ & 1E6 \\
\hline Confining stresses, $\sigma(\mathrm{kPa})$ & $\begin{array}{l}\sigma_{x}=\sigma_{y}=100 \text { (isotropic) } \\
\sigma_{x}=65, \sigma_{y}=130 \text { (anisotropic) }\end{array}$ & $\begin{array}{l}\sigma_{x}=\sigma_{y}=100 \text { (isotropic) } \\
\sigma_{x}=65, \sigma_{y}=130 \text { (anisotropic) }\end{array}$ \\
\hline Cohesion $^{a}, c(\mathrm{kPa})$ & 27.14 & 0 \\
\hline Friction angle ${ }^{a}, \phi$ (degree) & 22.61 & 40.56 \\
\hline Tensile strength $^{a}, \sigma_{t}(\mathrm{kPa})$ & 5.14 & 0 \\
\hline
\end{tabular}

\footnotetext{
${ }^{a}$ Based on results of numerical simulations of plane strain tests from this study.
} 
Table 5. Verifications of fracturing pressures based on the proposed mode of hydraulic fracturing.

\begin{tabular}{|c|c|c|c|c|}
\hline \multirow[b]{2}{*}{ Field or numerical case ${ }^{a}$} & \multirow[b]{2}{*}{ Observed situations } & \multicolumn{2}{|c|}{$\begin{array}{l}\text { Predicted hydrofracturing } \\
\text { pressure } p_{f}(\mathrm{kPa})\end{array}$} & \multirow[b]{2}{*}{ Comments on prediction accuracy } \\
\hline & & $\begin{array}{l}\text { Type I } \\
\text { (punching } \\
\text { shear only) }\end{array}$ & $\begin{array}{l}\text { Type II } \\
\text { (punching + } \\
\text { splitting) }\end{array}$ & \\
\hline $\begin{array}{l}\text { Field grouting } \\
\text { Depth: } 4.74 \mathrm{~m} \\
\text { Soil: CL }\end{array}$ & $\begin{array}{l}\text { Hydraulic fracturing with } \\
\text { pressure } p_{f} \approx 150 \mathrm{kPa}\end{array}$ & 109 & 167 & $-27 \%$ error (Type I); $+11 \%$ error (Type II) \\
\hline $\begin{array}{l}\text { Field grouting } \\
\text { Depth: } 5.74 \mathrm{~m} \\
\text { Soil: SM1 }\end{array}$ & $\begin{array}{l}\text { Hydraulic fracturing with } \\
\text { pressure } p_{f} \approx 200 \mathrm{kPa}\end{array}$ & 137 & 195 & $-32 \%$ error (Type I); $-3 \%$ error (Type II) \\
\hline $\begin{array}{l}\text { Field grouting } \\
\text { Depth: } 6.74 \mathrm{~m} \\
\text { Soil: SM2/ML }\end{array}$ & $\begin{array}{l}\text { Hydraulic fracturing with } \\
\text { pressure } p_{f} \approx 225 \mathrm{kPa}\end{array}$ & 149 & 234 & $-34 \%$ error (Type I) $+4 \%$ error (Type II) \\
\hline $\begin{array}{l}\text { Field grouting } \\
\text { Depth: } 8.07 \mathrm{~m} \\
\text { Soil: ML }\end{array}$ & $\begin{array}{l}\text { Hydraulic fracturing with } \\
\text { pressure } p_{f} \approx 270 \mathrm{kPa}\end{array}$ & 182 & 282 & $-33 \%$ error (Type I); $+4 \%$ error (Type II) \\
\hline $\begin{array}{l}\text { Numerical simulations in Clay } \\
\text { with } \sigma_{x}=\sigma_{y}=100 \mathrm{kPa} \\
\& \text { injection pressure } p_{i n j}= \\
350 \mathrm{kPa}\end{array}$ & $\begin{array}{l}\text { No hydraulic fracturing } \\
\text { observed }\end{array}$ & $306^{b}$ & $411^{b}$ & $\begin{array}{l}\text { As predicted by Type II mode with no hy- } \\
\text { draulic fracturing }\end{array}$ \\
\hline $\begin{array}{l}\text { Numerical simulations in Clay } \\
\text { with } \sigma_{x}=65 \mathrm{kPa}, \sigma_{y}=130 \mathrm{kPa} \\
\& \text { injection pressure } p_{i n j}= \\
350 \mathrm{kPa}\end{array}$ & $\begin{array}{l}\text { Hydraulic fracturing } \\
\text { observed }\end{array}$ & $228^{b}$ & $298^{b}$ & $\begin{array}{l}\text { As predicted by Types I \& II modes with } \\
\text { hydraulic fracturing. By judging the } \\
\text { computed fracture conditions, however, } \\
\text { Type II mode would appear more likely. }\end{array}$ \\
\hline $\begin{array}{l}\text { Numerical simulations in Sand } \\
\text { with } \sigma_{x}=\sigma_{y}=100 \mathrm{kPa} \\
\& \text { injection pressure } p_{i n j}= \\
350 \mathrm{kPa}\end{array}$ & $\begin{array}{l}\text { No hydraulic fracturing } \\
\text { observed }\end{array}$ & $472^{b}$ & $572^{b}$ & $\begin{array}{l}\text { As predicted by Types I \& II modes with no } \\
\text { hydraulic fracturing. By judging the } \\
\text { computed injection conditions, however, } \\
\text { Type II would appear more likely. }\end{array}$ \\
\hline $\begin{array}{l}\text { Numerical simulations in Sand } \\
\text { with } \sigma_{x}=65 \mathrm{kPa}, \sigma_{y}=130 \mathrm{kPa} \\
\& \text { injection pressure } p_{i n j}= \\
350 \mathrm{kPa}\end{array}$ & $\begin{array}{l}\text { Hydraulic fracturing } \\
\text { observed (liquefac- } \\
\text { tion-like) }{ }^{c}\end{array}$ & $307^{b}$ & $372^{b}$ & $\begin{array}{l}\text { Type I mode predicts the fracturing, but } \\
\text { Type II doesn't. However, the numerical } \\
\text { results show the observed fractures are of } \\
\text { a liquefaction-like, due to the fact that } \\
\text { excess pore pressures are induced in the } \\
\text { sand around the grout hole by the injected } \\
\text { fluid. Since we do not consider the excess } \\
\text { pore pressures in the proposed modes, the } \\
\text { Type II prediction should slightly overes- } \\
\text { timate and the Type I prediction would be } \\
\text { substantially lower than the fracturing } \\
\text { pressure. }\end{array}$ \\
\hline
\end{tabular}


$<<$ Fig. 1 $>>-$ Site plan and soil profile.

Fig. 1. Site plan and soil profile.

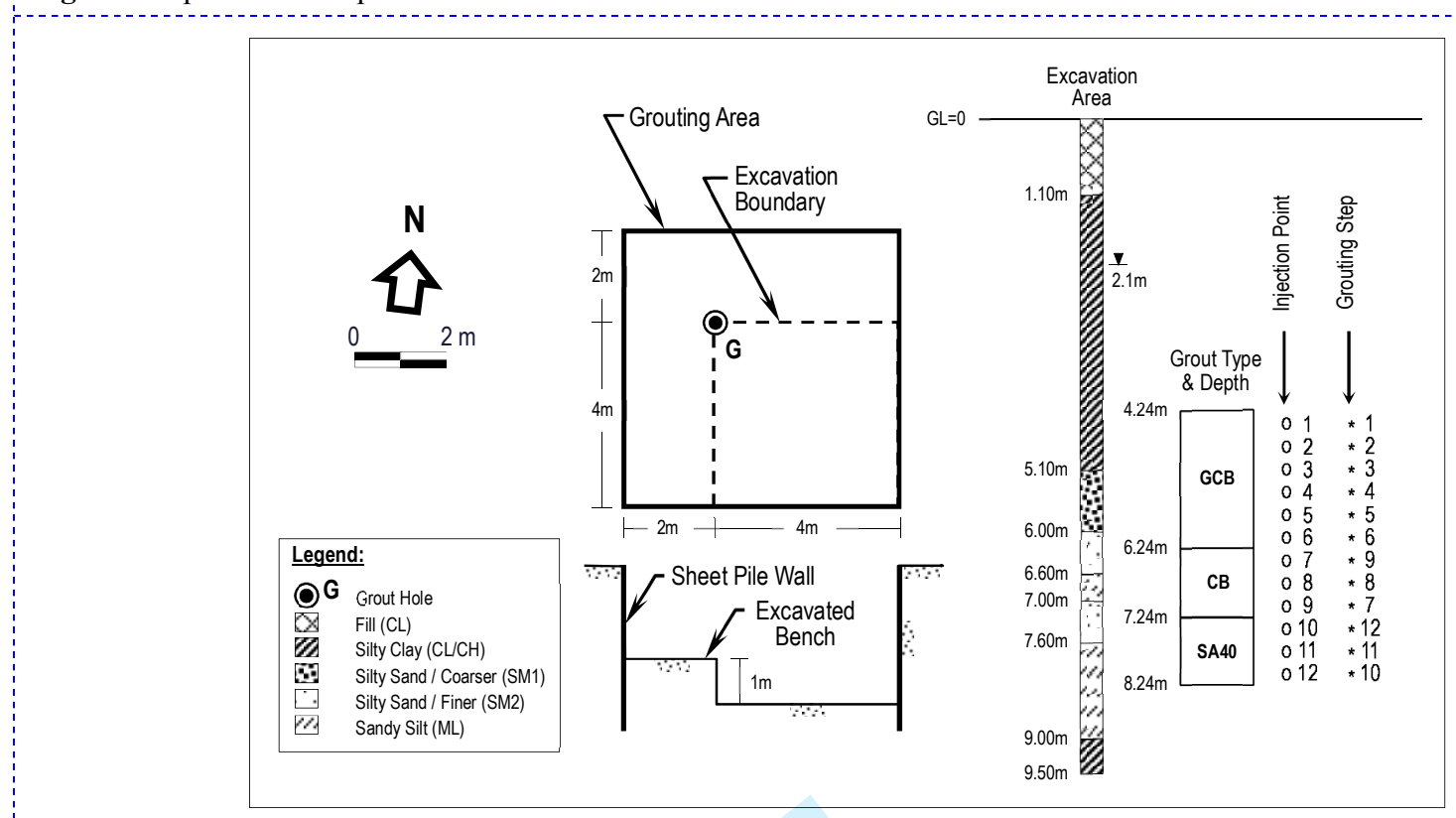




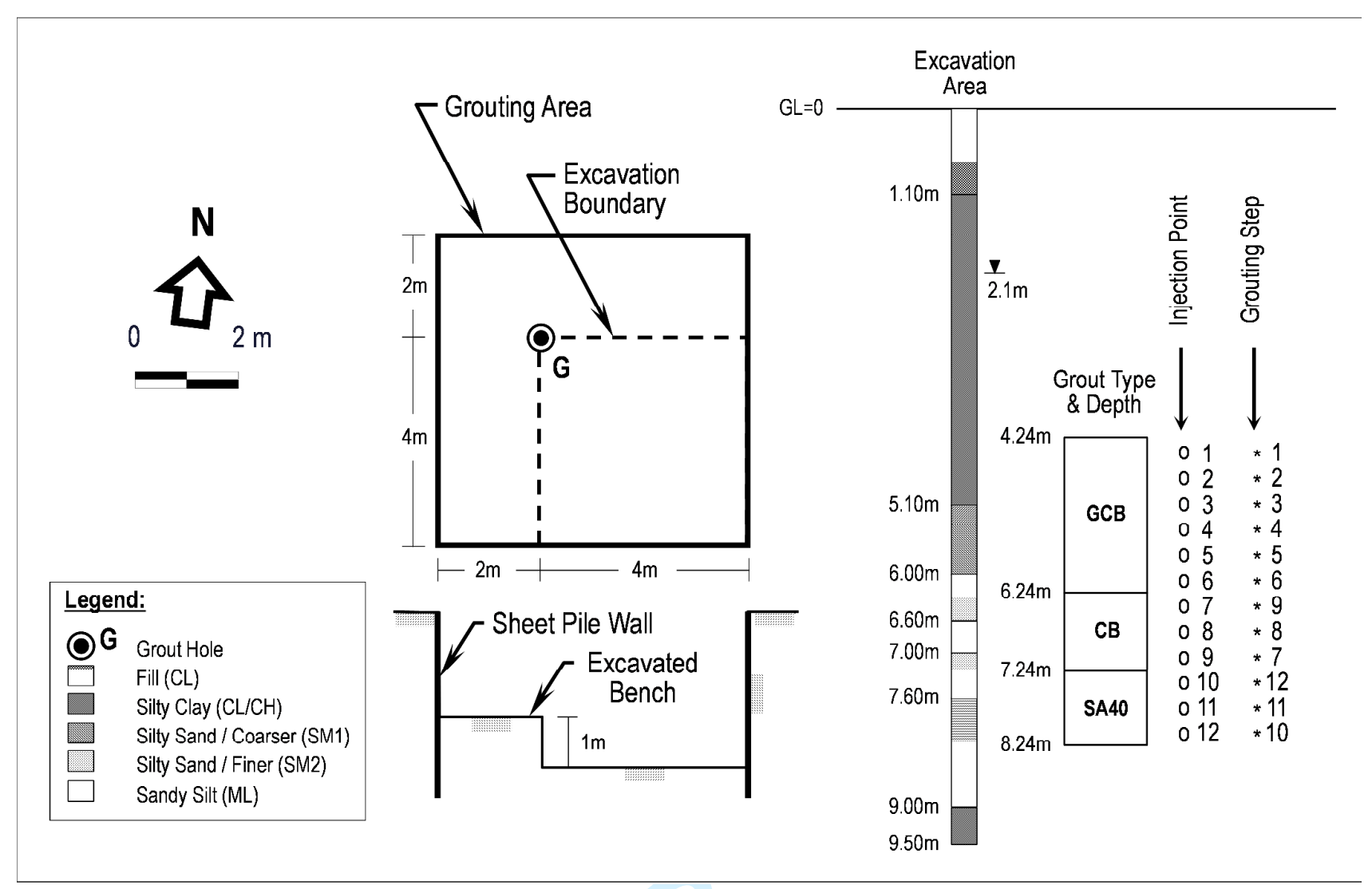


$<<$ Fig. $2>>$ - Soil grouting by tube-á-manchette (TAM).

Fig. 2. Soil grouting by tube-á-manchette (TAM).
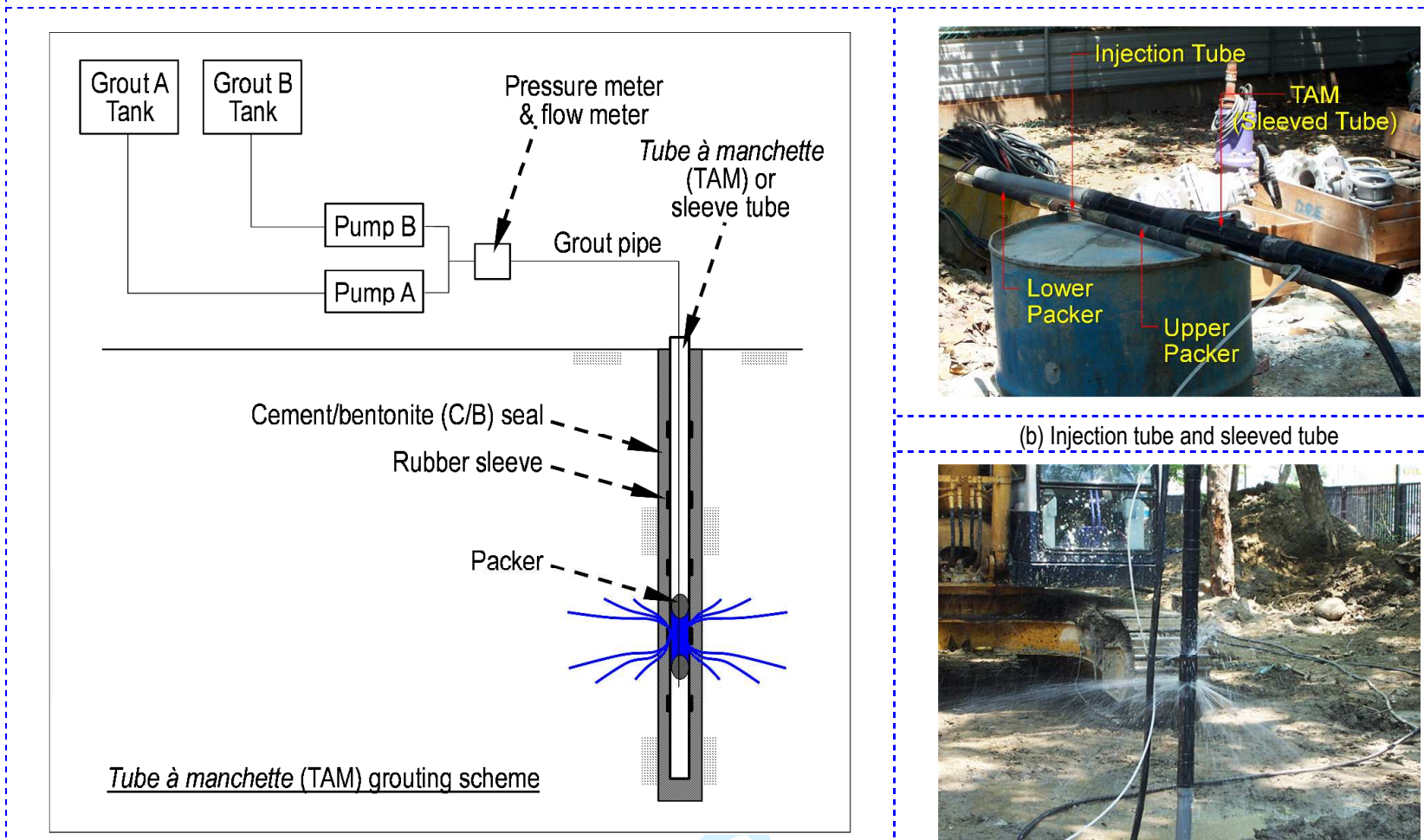

(b) Injection tube and sleeved tube

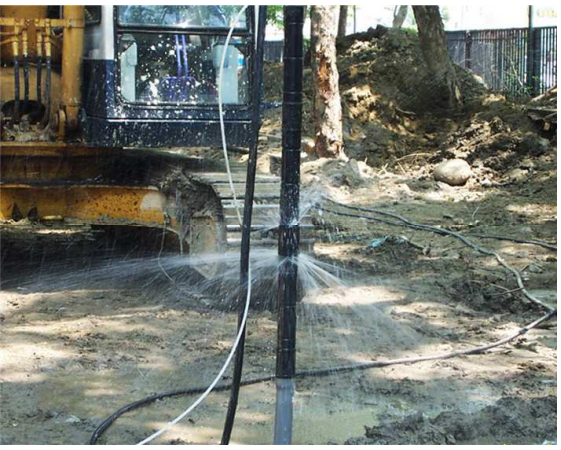

(a) Schematic illustration of the grouting setup

(c) Injection trial with water 
-- Fig. 2(a)

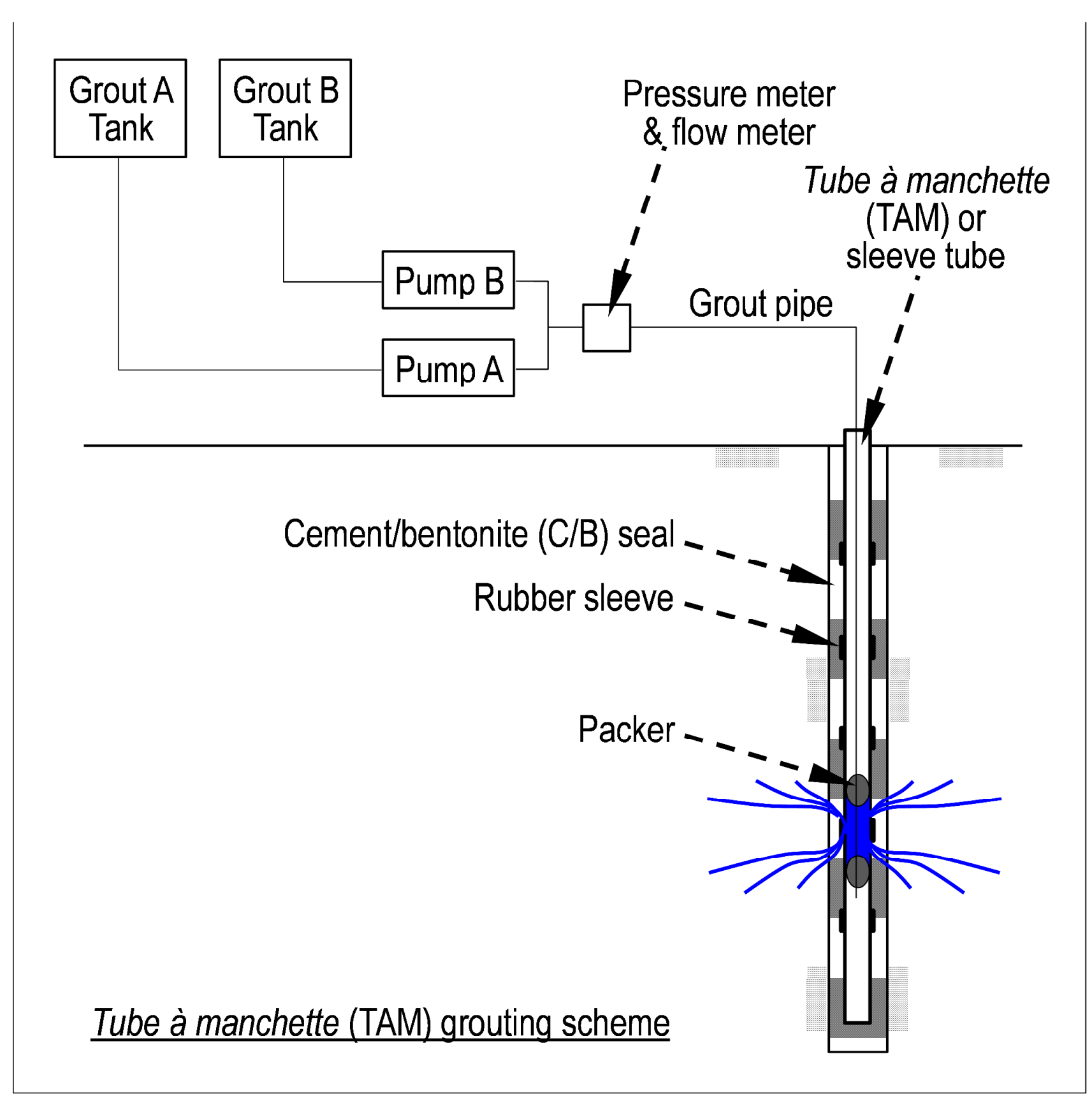




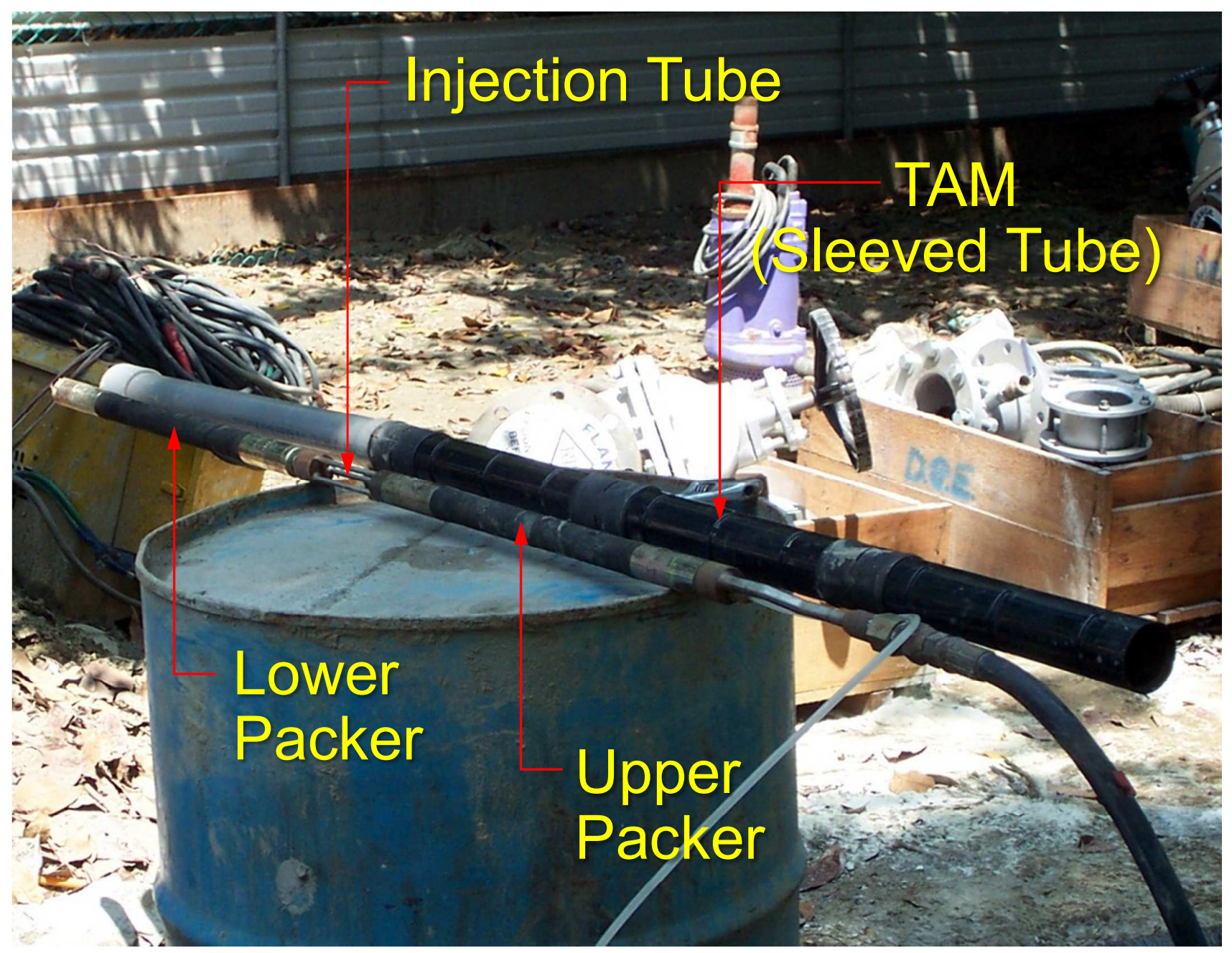


-- Fig. 2(c)

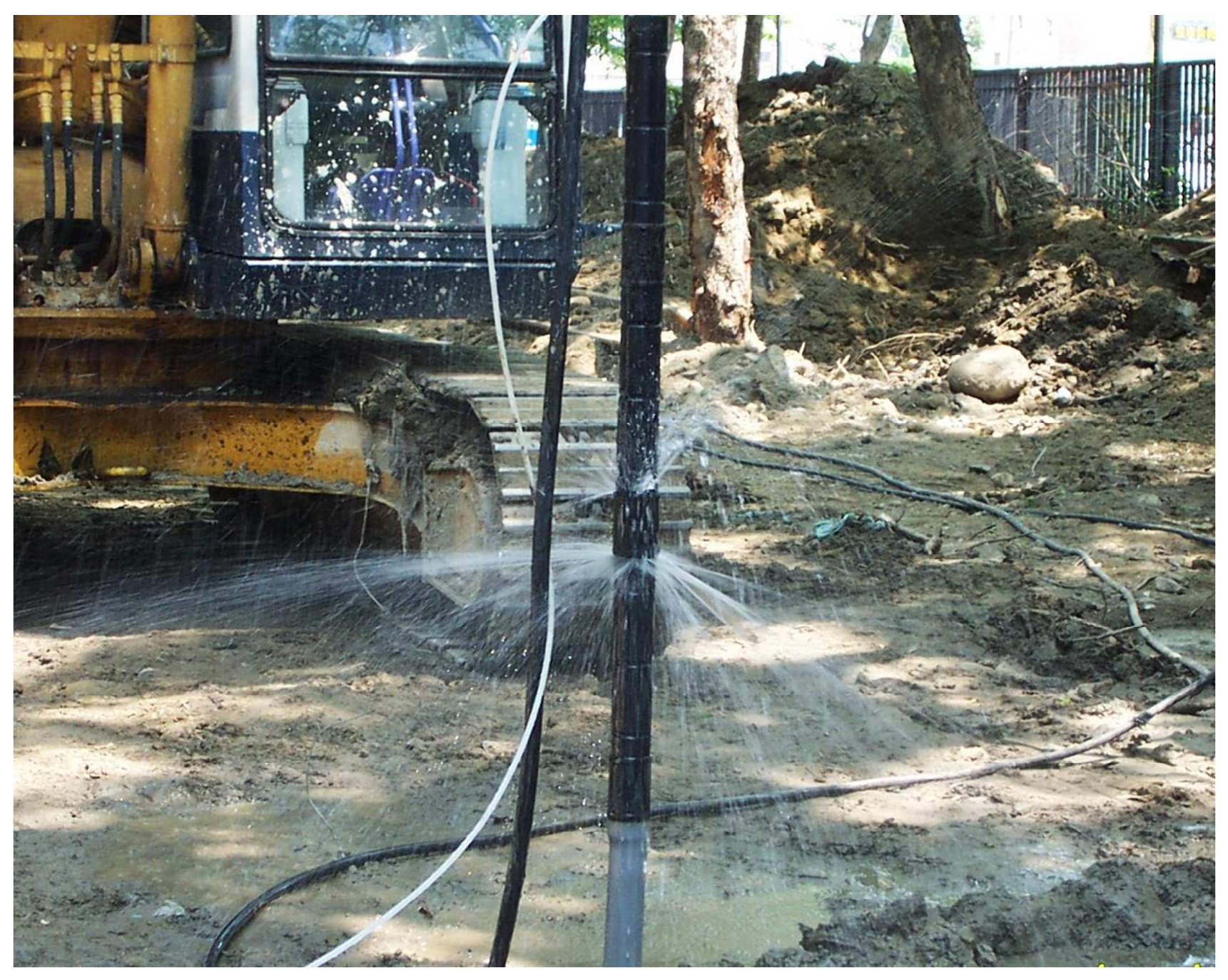


$<<$ Fig. 3 $>>$ - Observations of grout emergence on the ground surface and grout traces in each of the excavation stages.

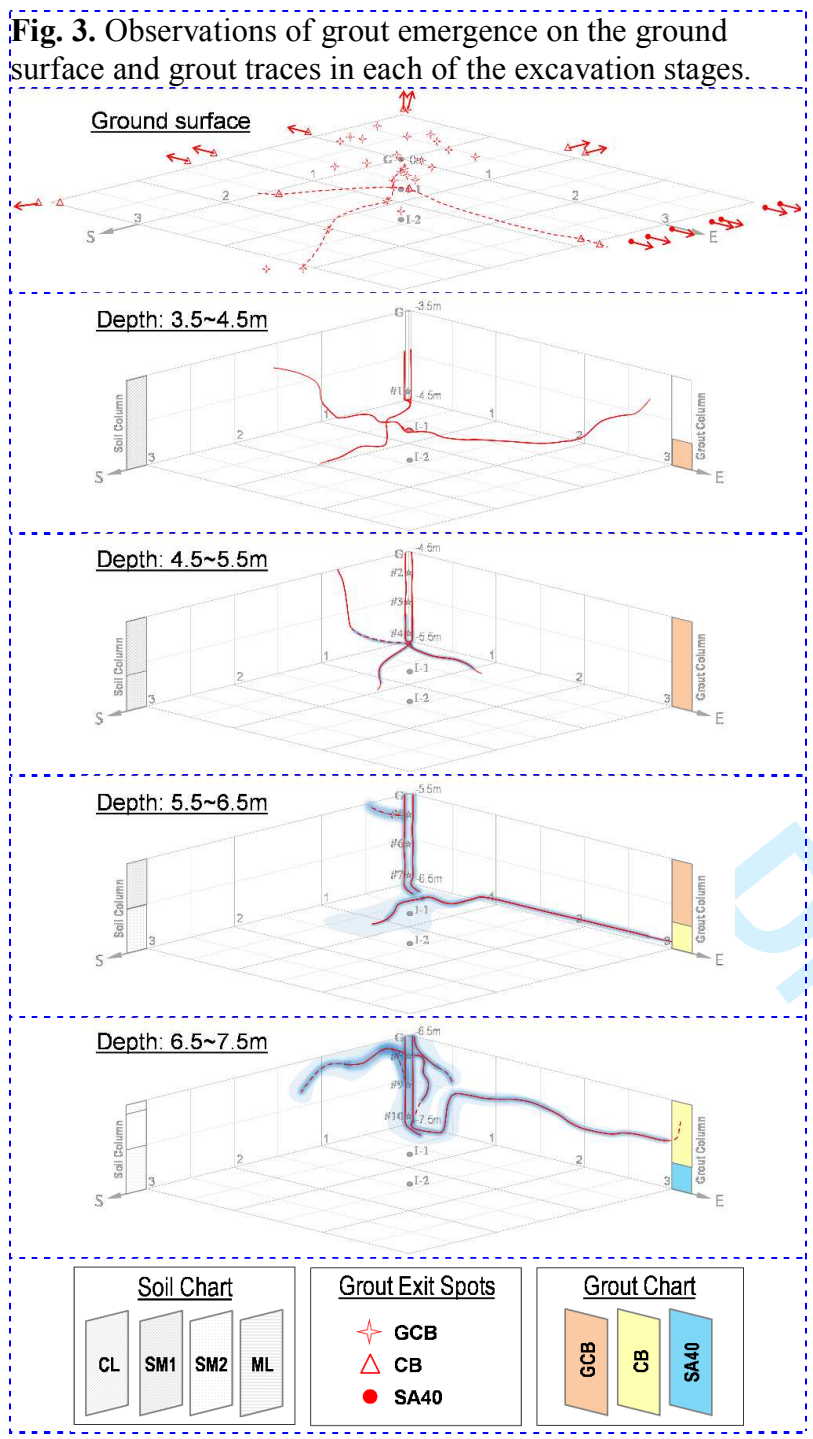



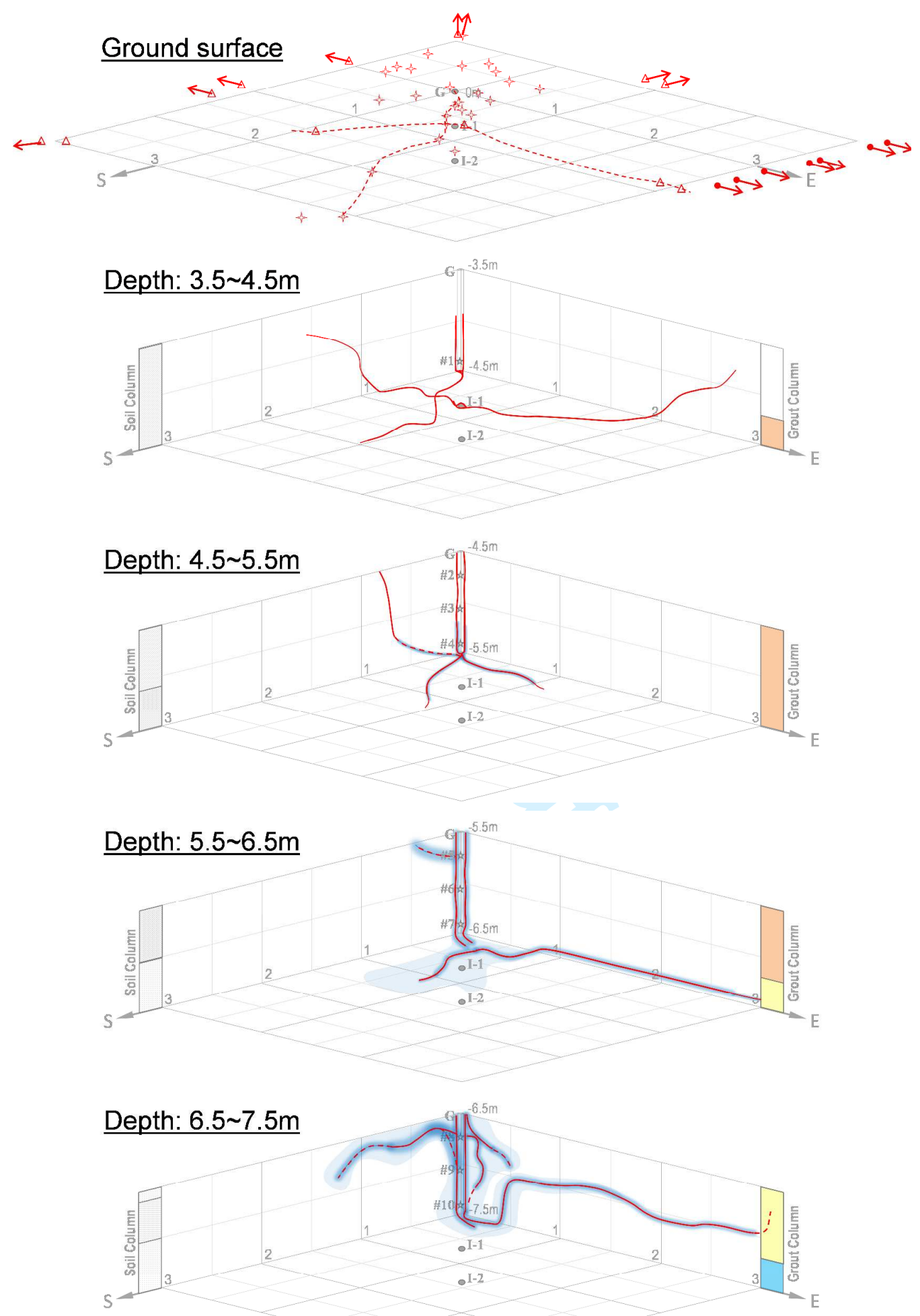


GL SM1 SM2


$<<$ Fig. 4>> - Injection pressure vs. injection rate relationship at Grouting Depth $7.41 \mathrm{~m}$ (Injection Point $\# 10)$.

Fig. 4. Injection pressure vs. injection rate relationship at Grouting Depth $7.41 \mathrm{~m}$ (Injection Point \#10).

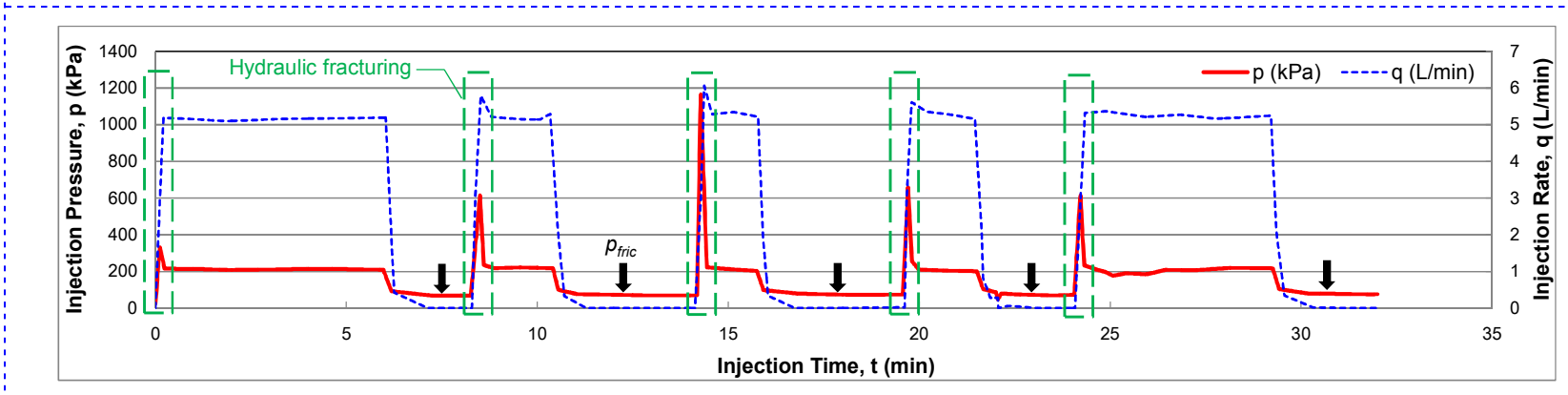

(a) Injection pressure \& injection rate time histories

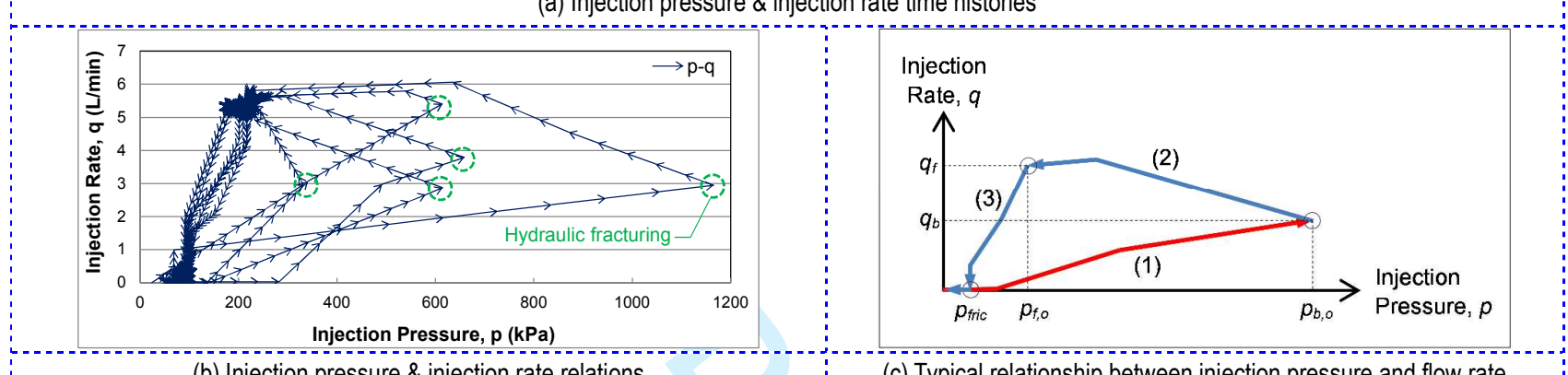

(b) Injection pressure \& injection rate relations

(c) Typical relationship between injection pressure and flow rate 
-- Fig. 4(a)

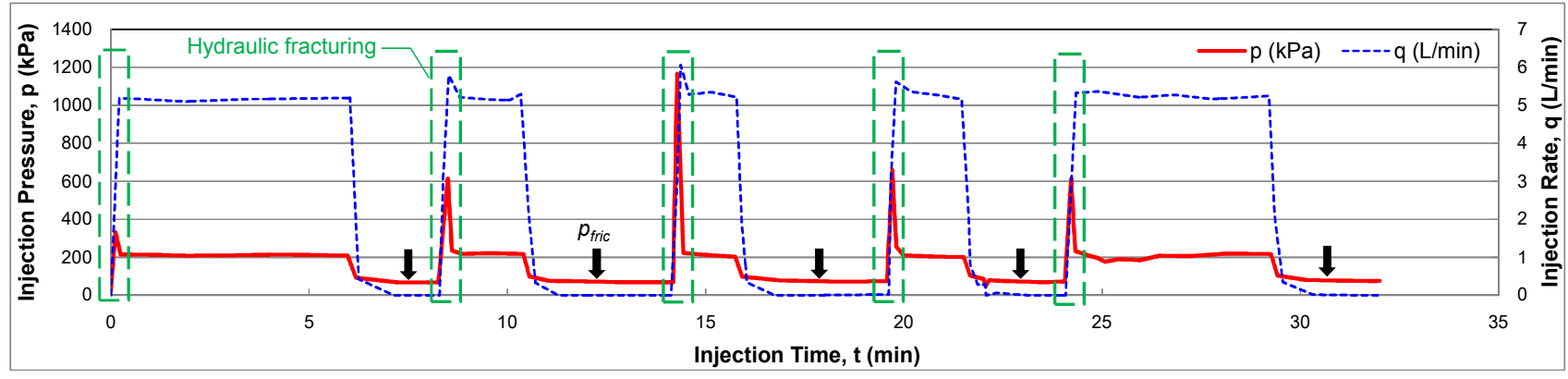




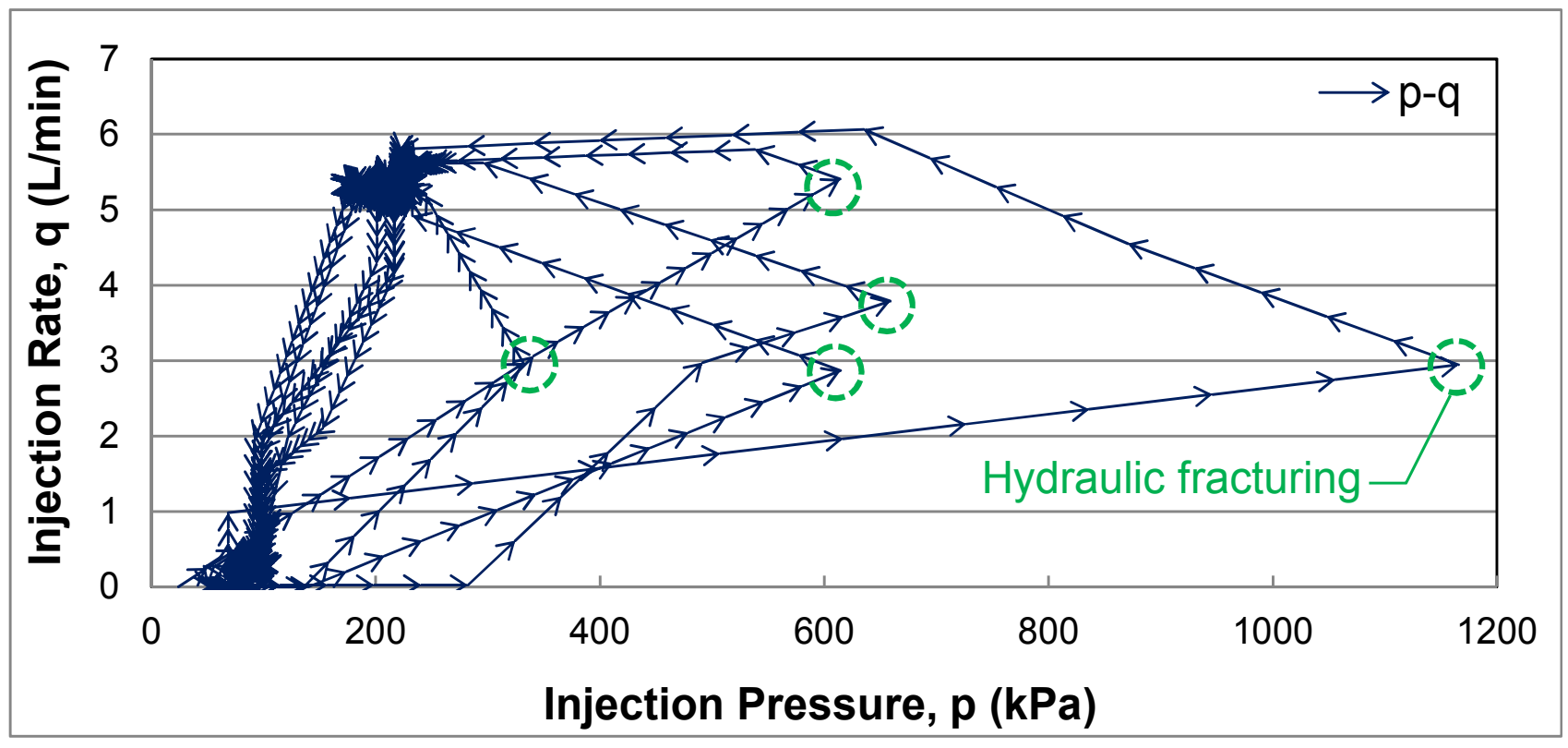




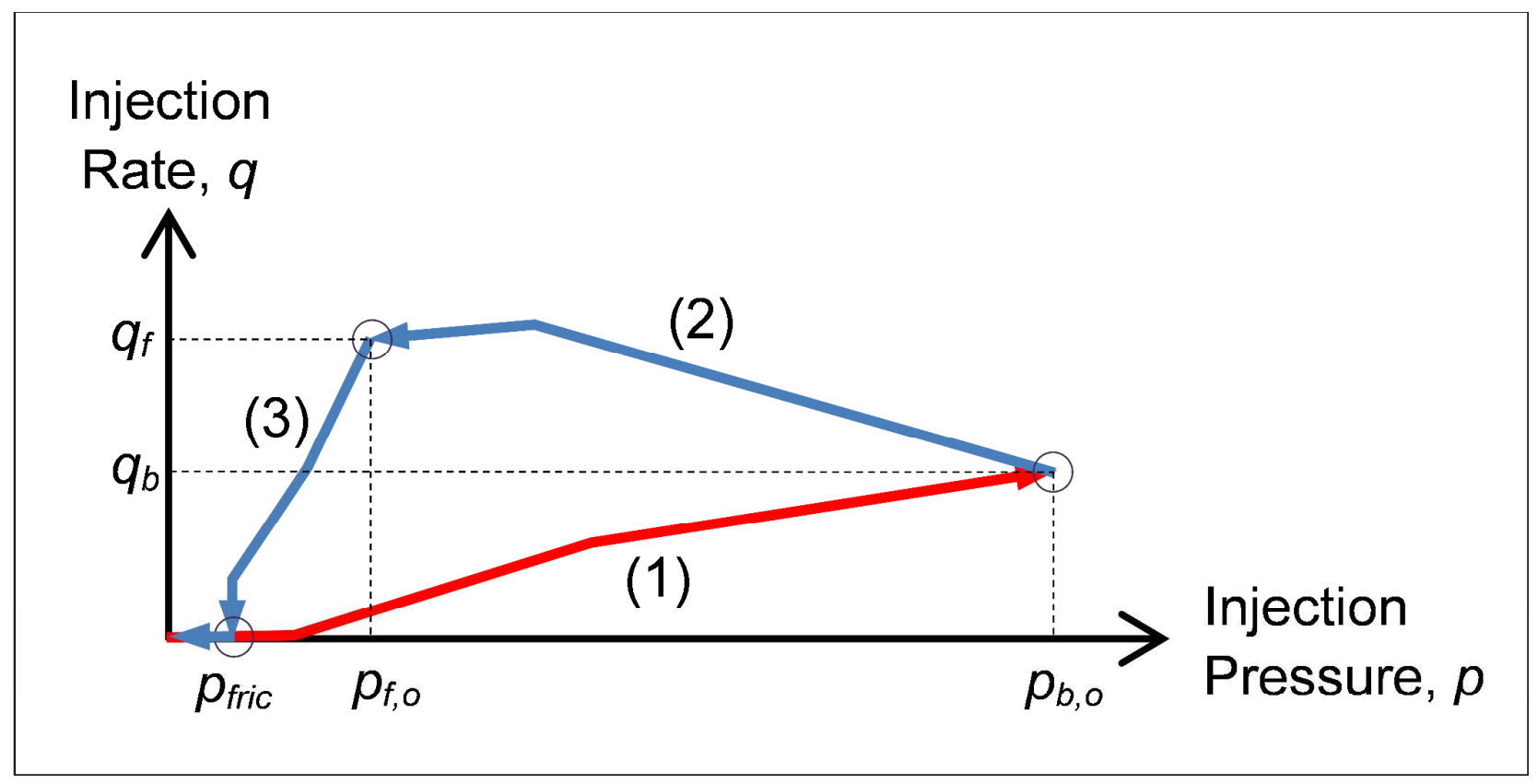


$<<$ Fig. 5>> - Bonding logic and fluid flow domain structure in $\mathrm{PFC}^{2 \mathrm{D}}$.

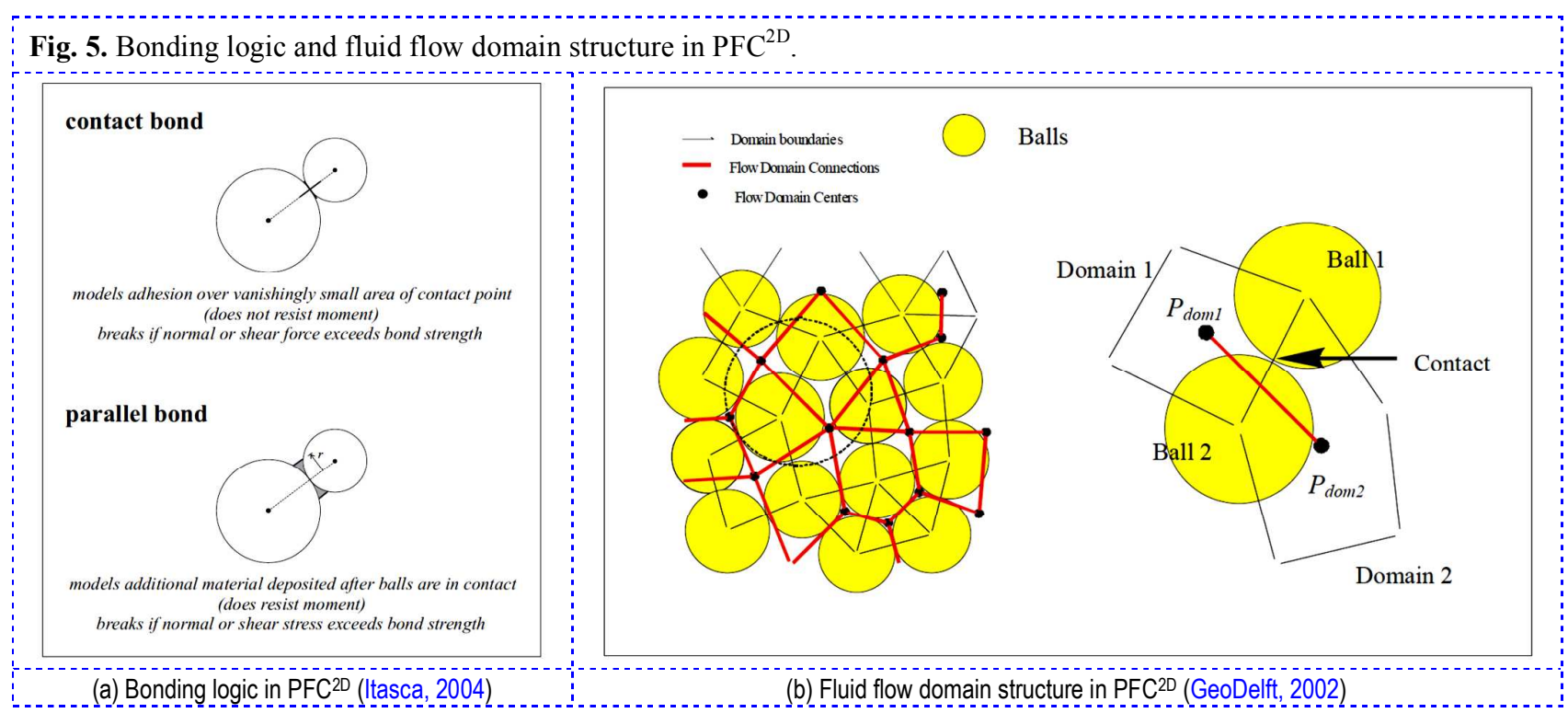




\section{contact bond}

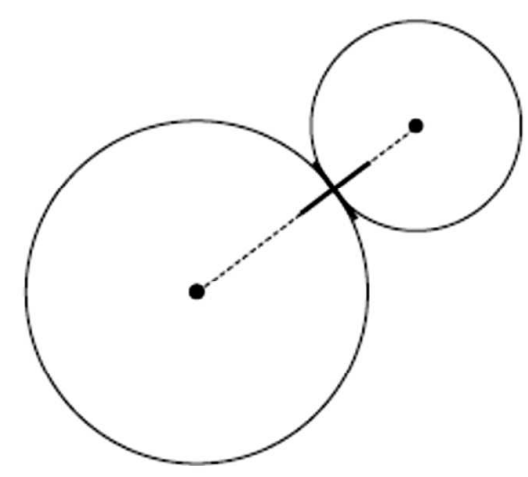

models adhesion over vanishingly small area of contact point (does not resist moment)

breaks if normal or shear force exceeds bond strength

\section{parallel bond}

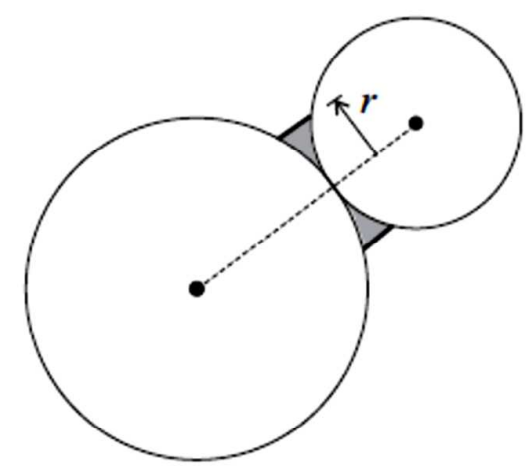

models additional material deposited after balls are in contact (does resist moment)

breaks if normal or shear stress exceeds bond strength 
-- Fig. 5(b)

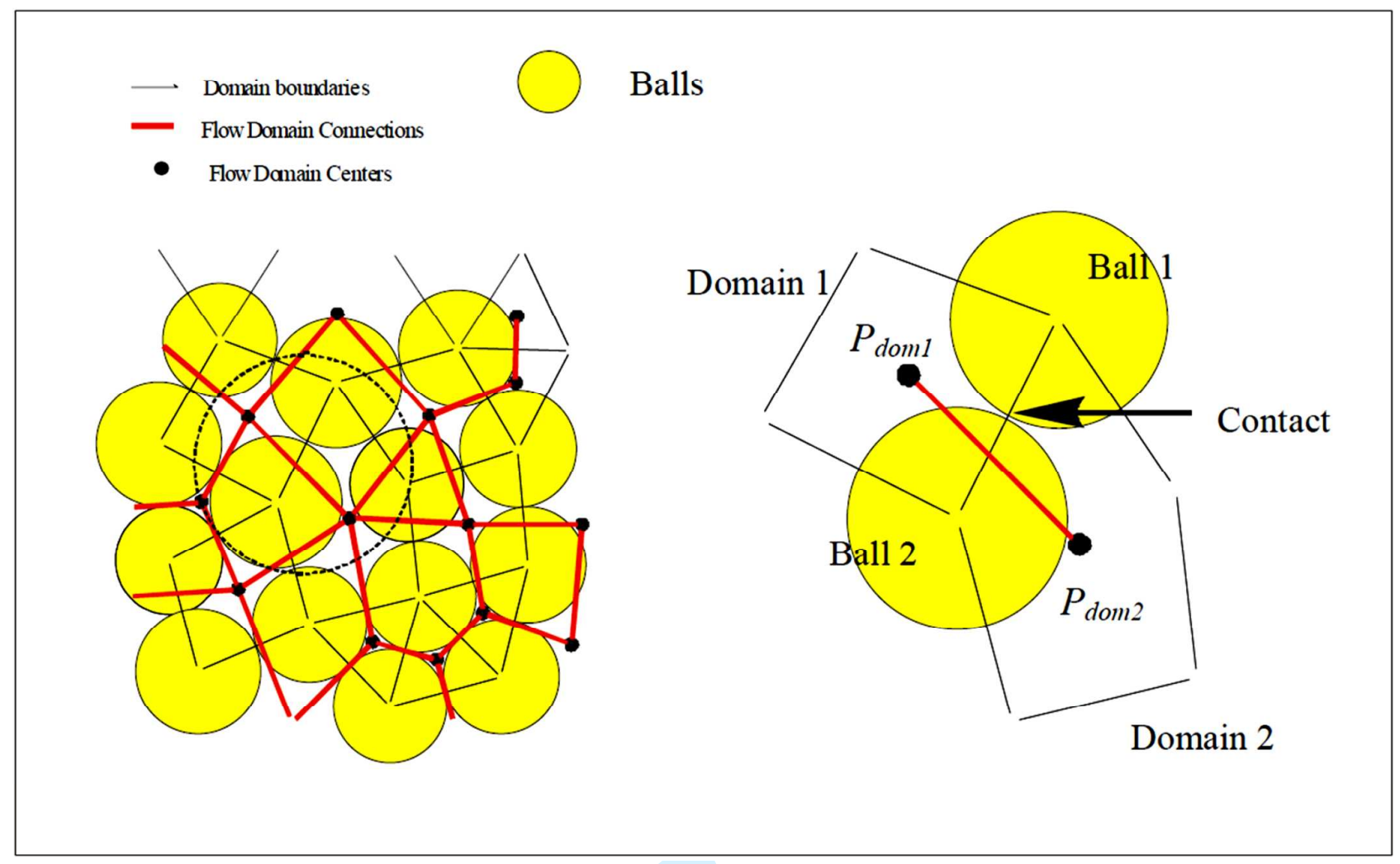


$<<$ Fig. 6 $>>-$ Numerical model for simulation of grouting in soil.

Fig. 6. Numerical model for simulation of grouting in soil.
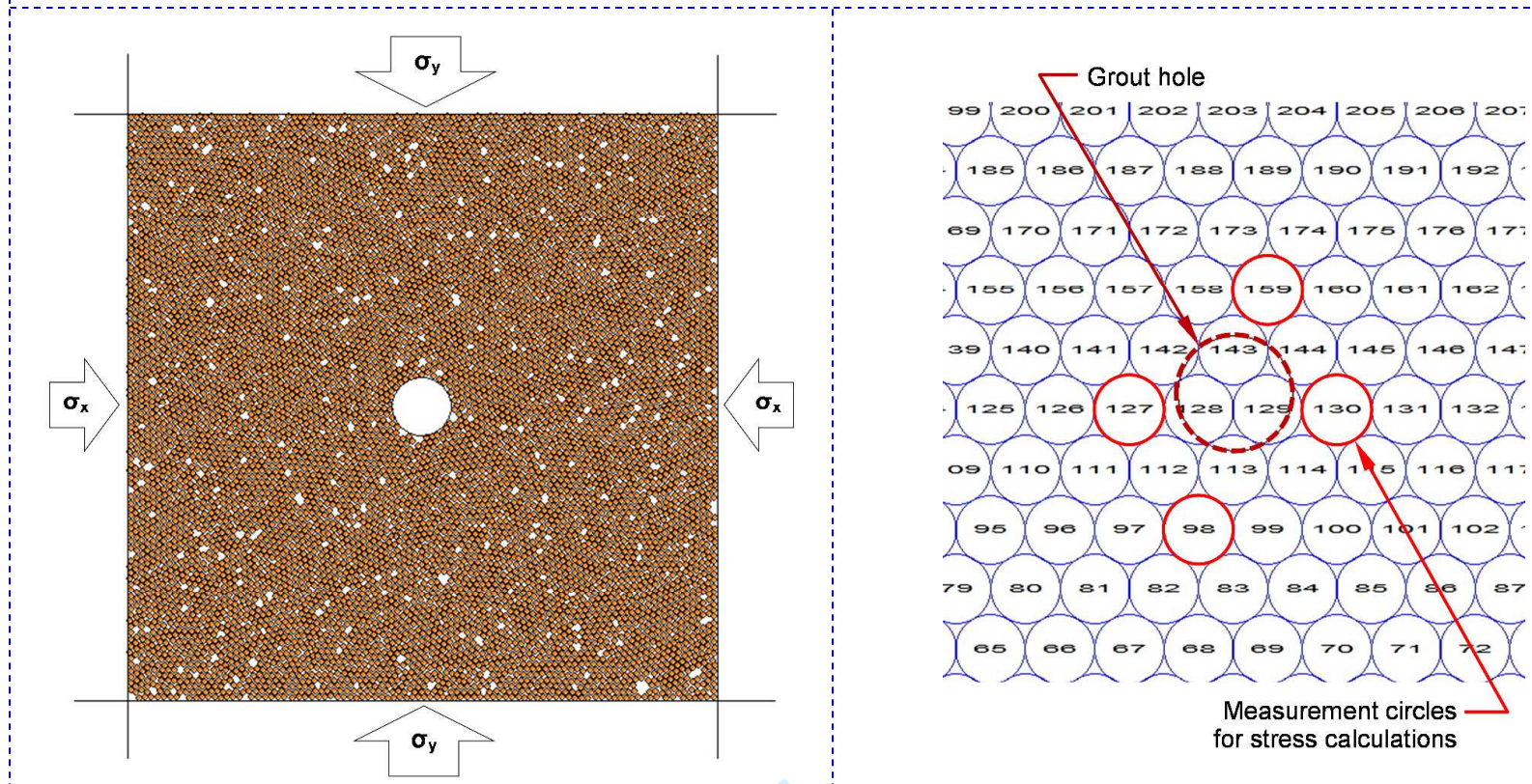

(a) $1 \mathrm{~m} \times 1 \mathrm{~m}$ particle assembly with a $0.1 \mathrm{~m}$-dia. central grout hole

(b) Grout hole and numbered measurement circles 
-- Fig. 6(a)

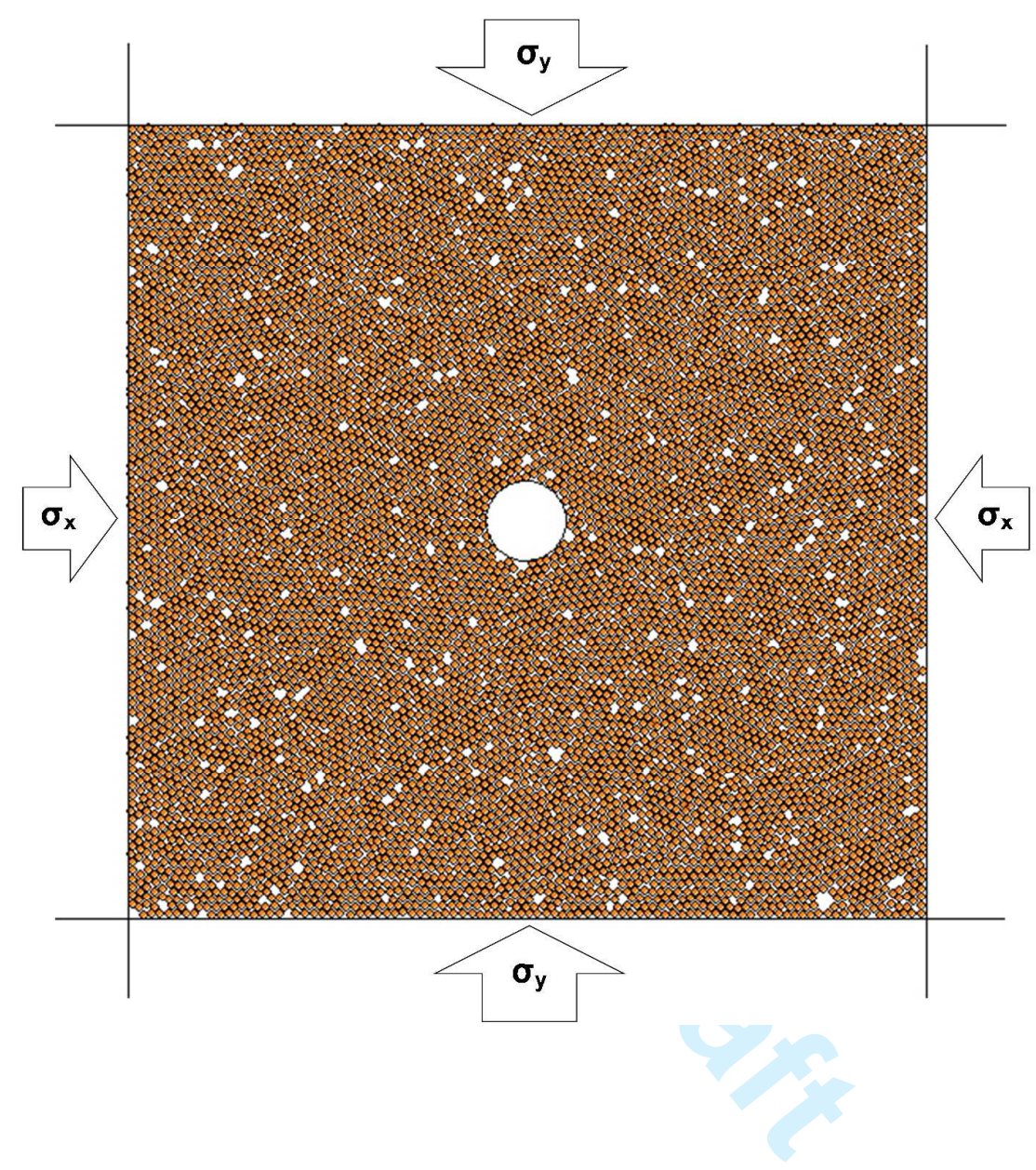




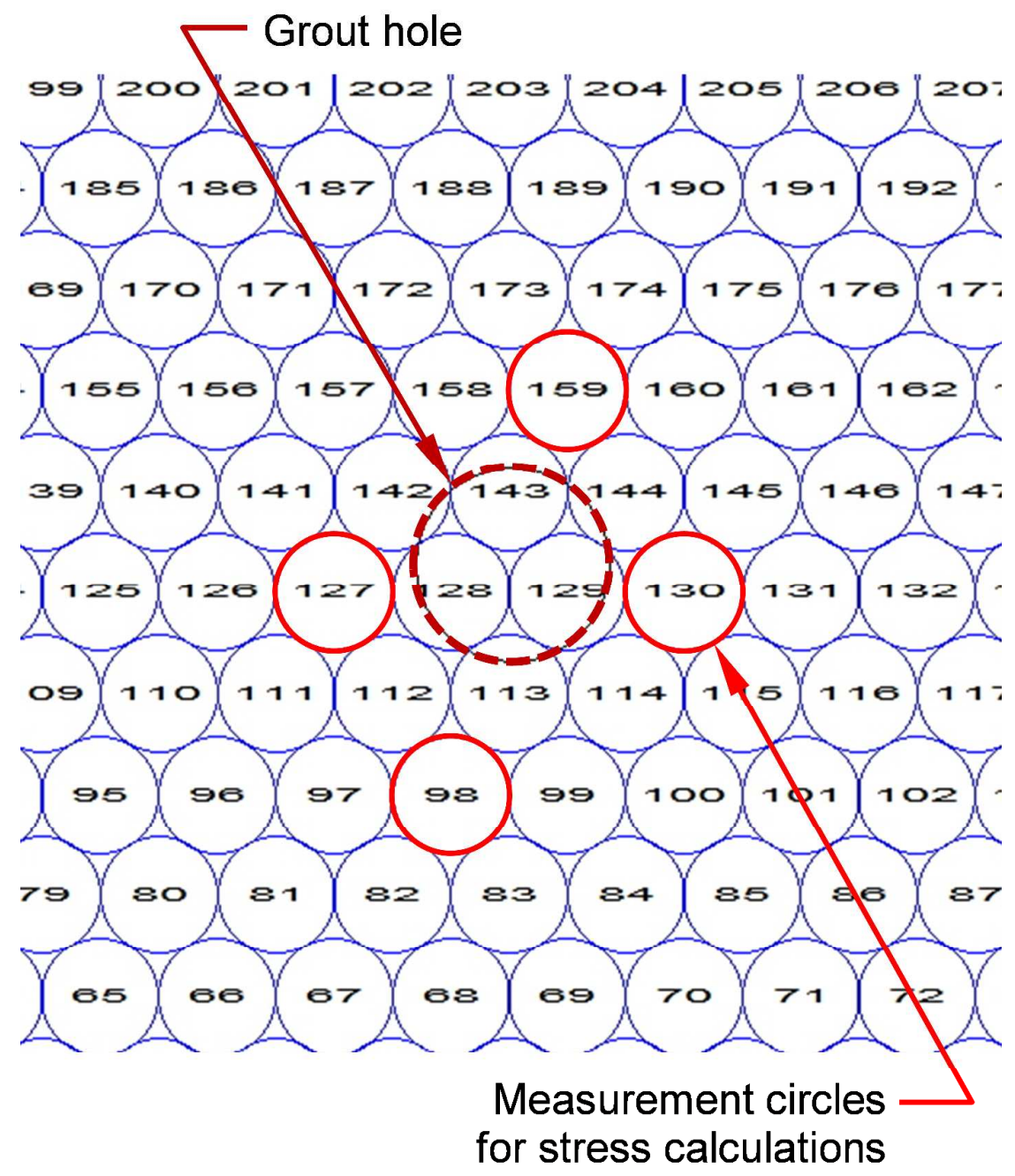


$<<$ Fig. $7>>-$ Numerical simulations of plane strain compressive and tensile tests for dry soils.

Fig. 7. Numerical simulations of plane strain compressive and tensile tests for soils.

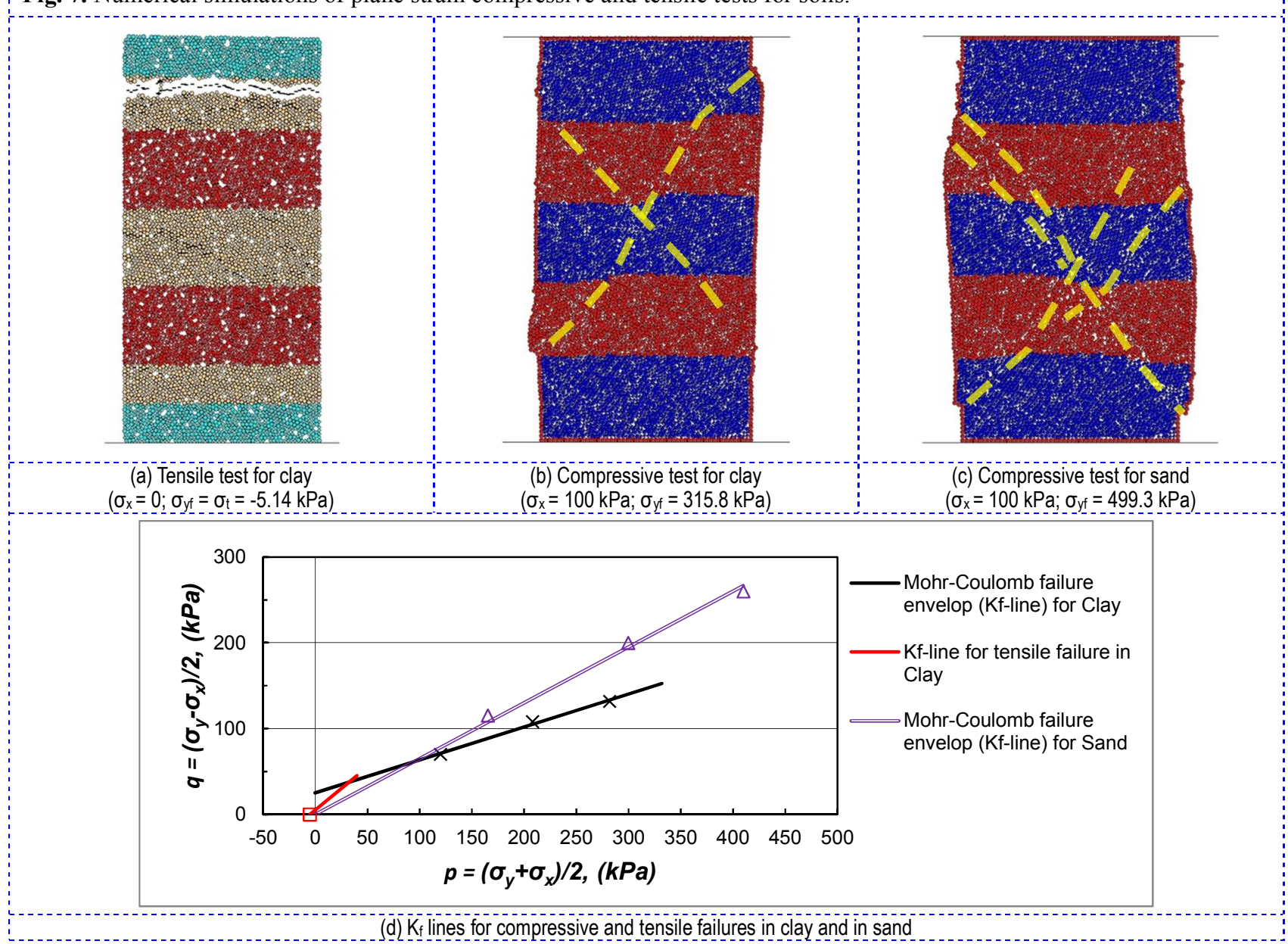


Fig. 7(a)

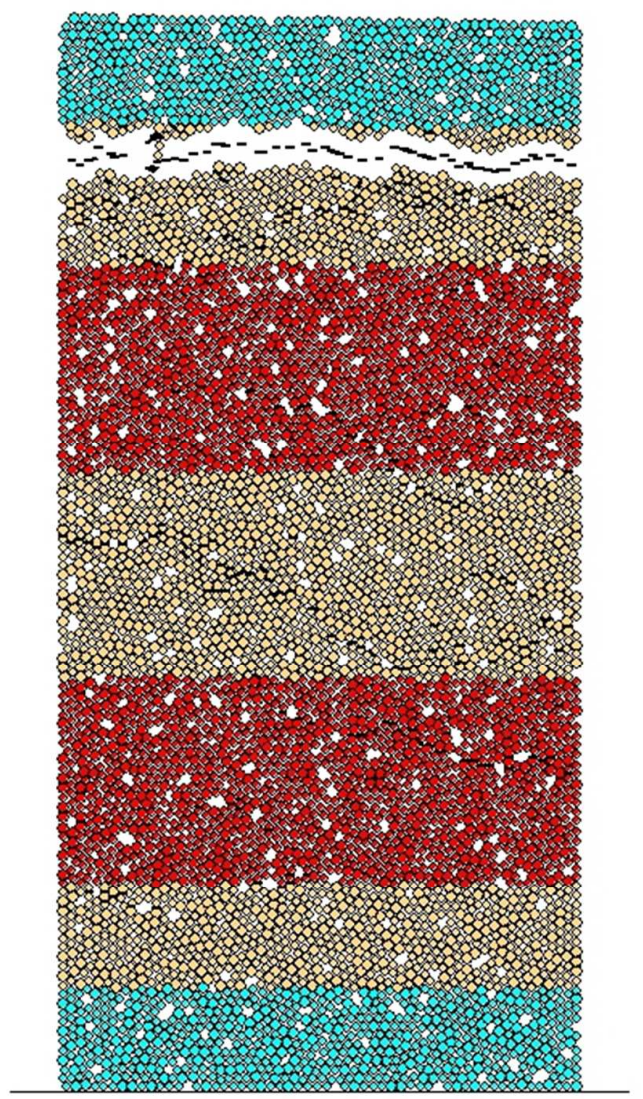


Fig. 7(b)

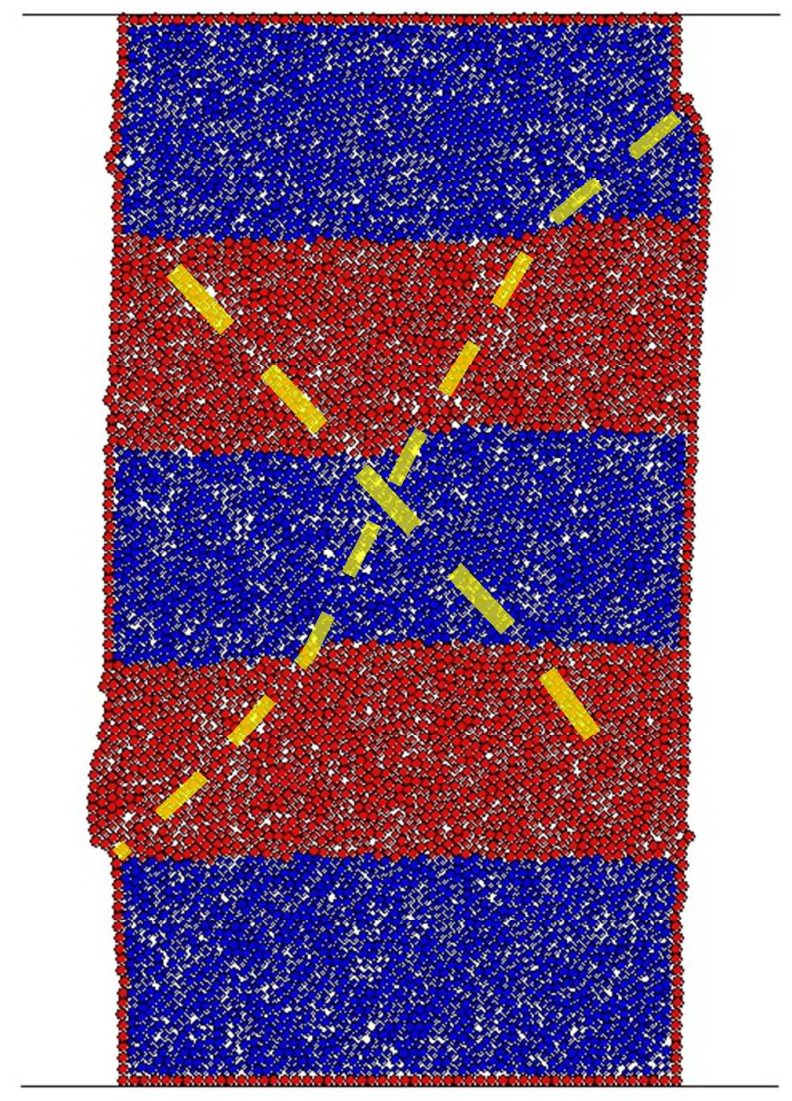


Fig. 7(c)

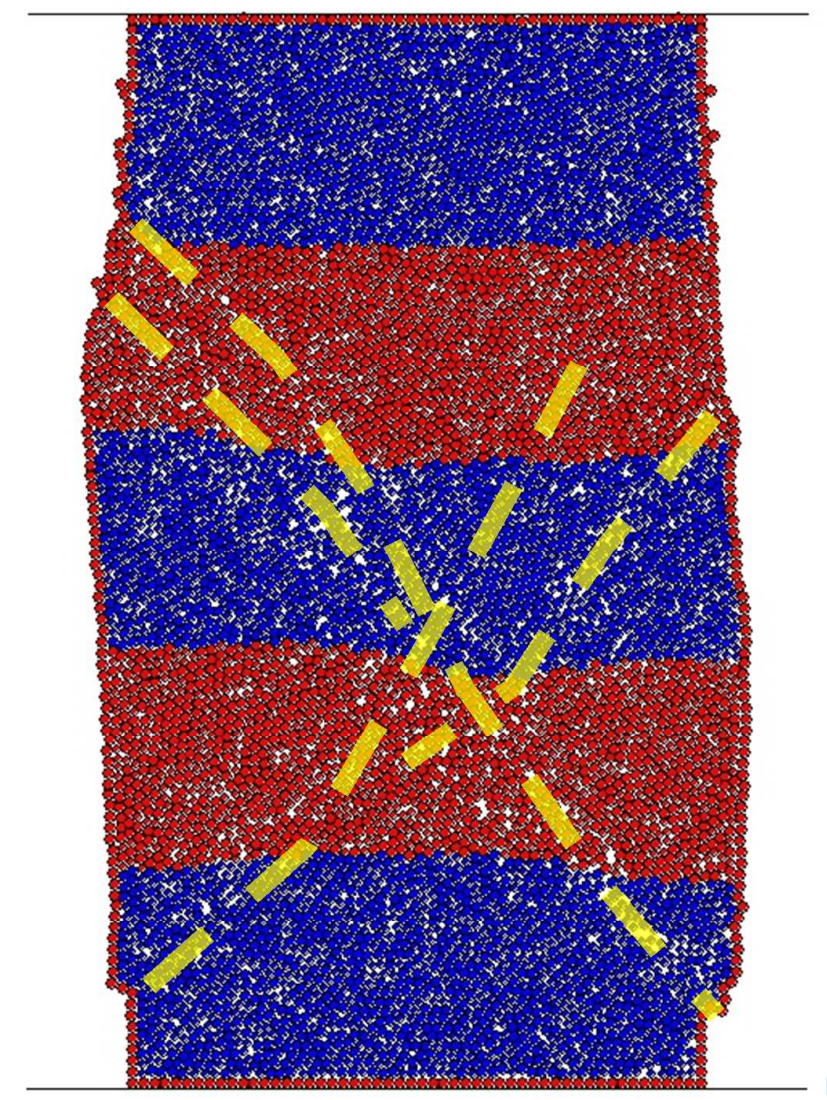


Fig. 7(d)

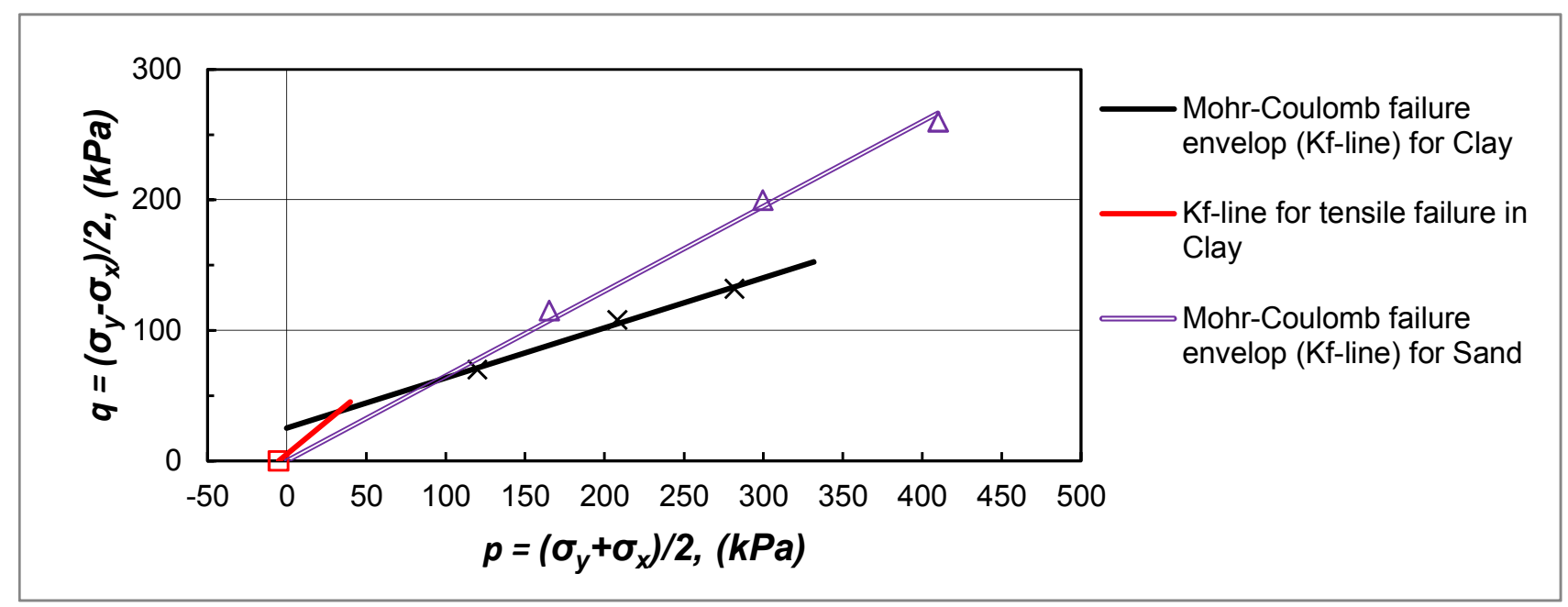


$<<$ Fig. $8>>-$ Numerical grouting in clayey and sandy soils $\left(\sigma_{\mathrm{x}}=\sigma_{\mathrm{y}}=100 \mathrm{kPa}, \mathrm{p}_{\mathrm{inj}}=350 \mathrm{kPa}, \mathrm{TS}=6000\right)$.

Fig. 8. Numerical grouting in clayey and sandy soils $\left(\sigma_{x}=\sigma_{y}=100 \mathrm{kPa}, p_{i n j}=350 \mathrm{kPa}, T S=6000\right)$.

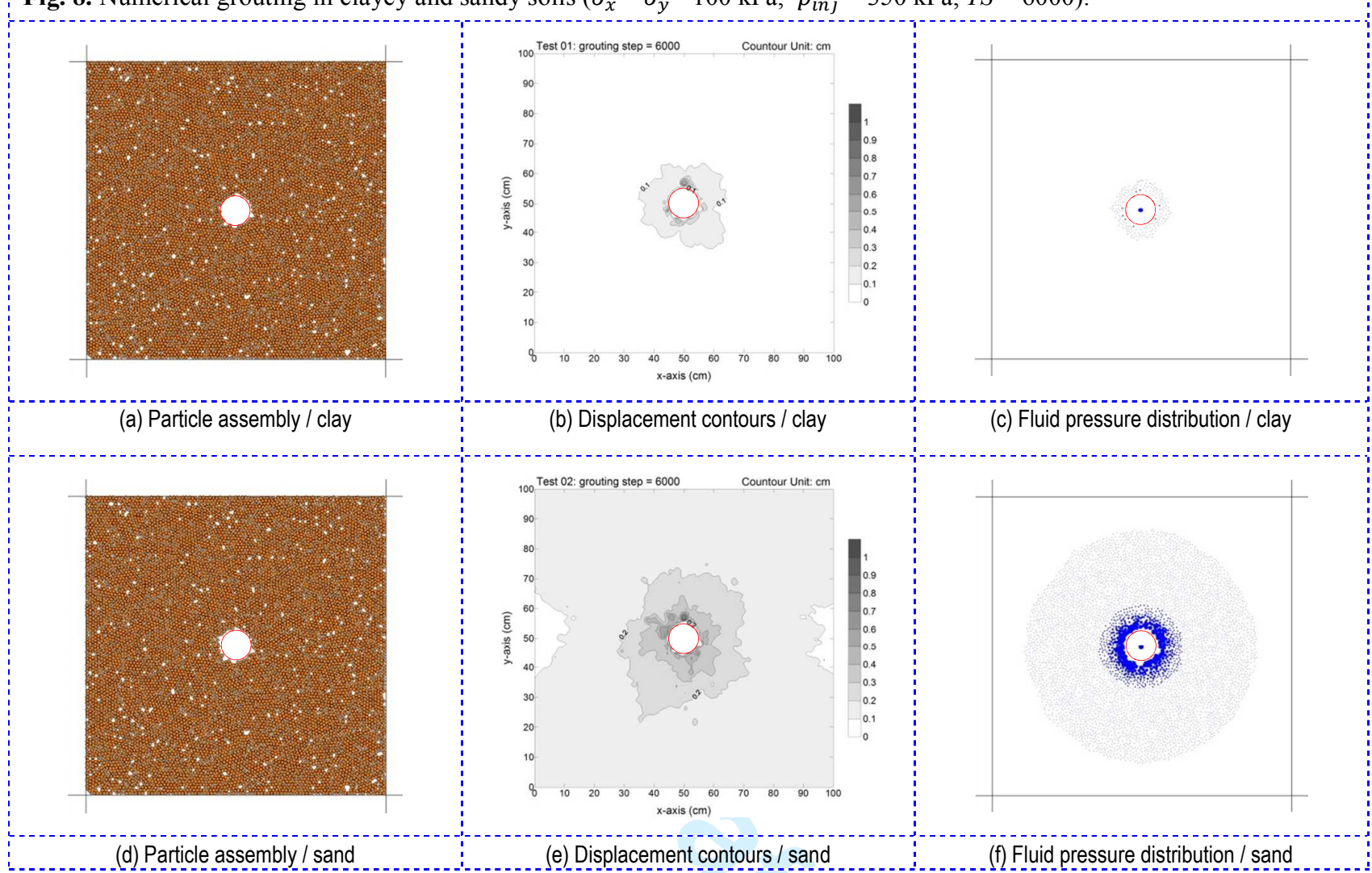


$<<$ Fig. 9 $>>-$ Effect of confining stress and stress anisotropy on grouting mechanism in clay $\left(\mathrm{p}_{\text {inj }}=350 \mathrm{kPa}\right)$.

Fig. 9. Effect of confining stress and stress anisotropy on grouting mechanism in clay $\left(p_{i n j}=350 \mathrm{kPa}\right)$.

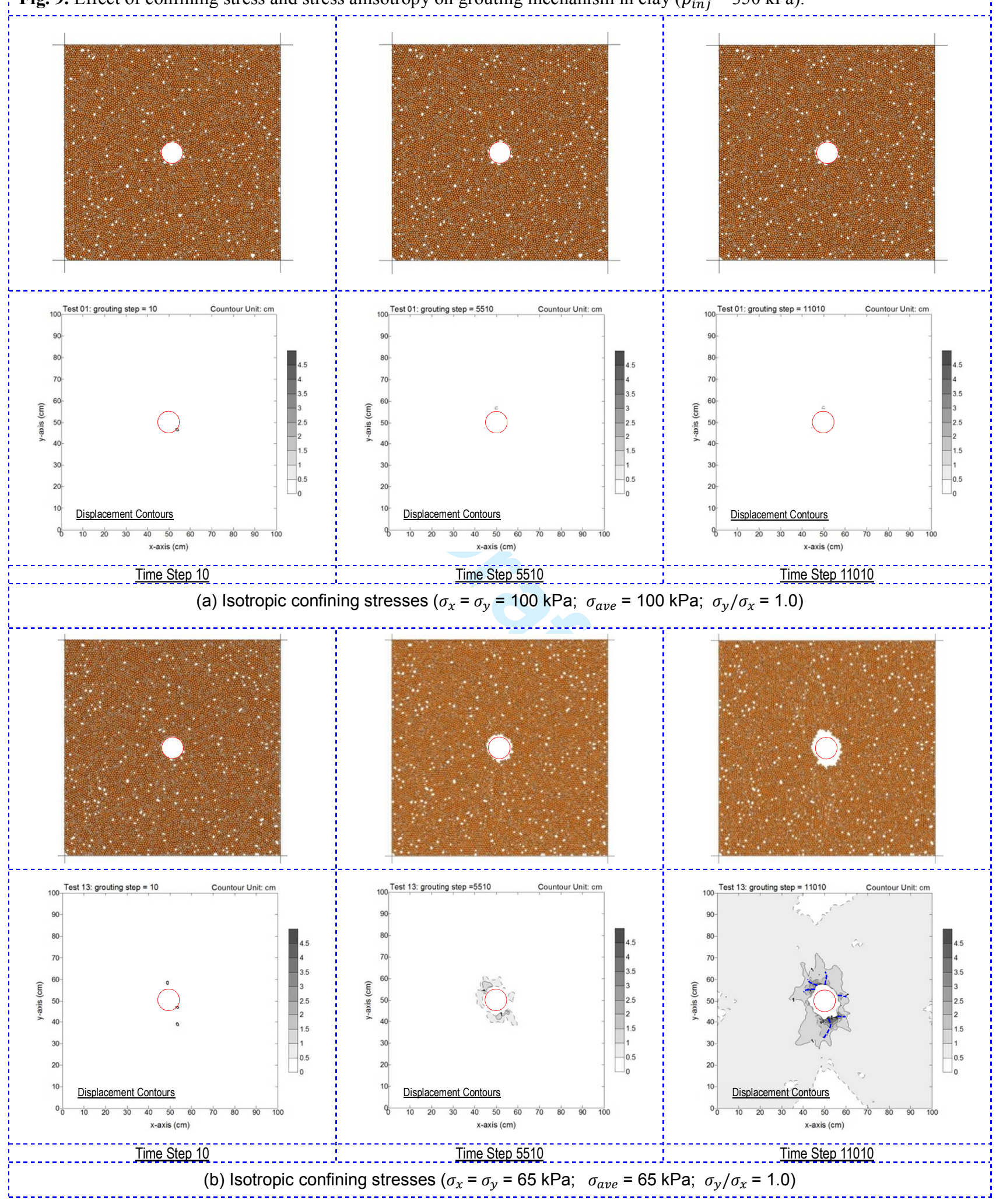


Fig. 9. Effect of confining stress and stress anisotropy on grouting mechanism in clay $\left(p_{\text {inj }}=350 \mathrm{kPa}\right)$ (continued).

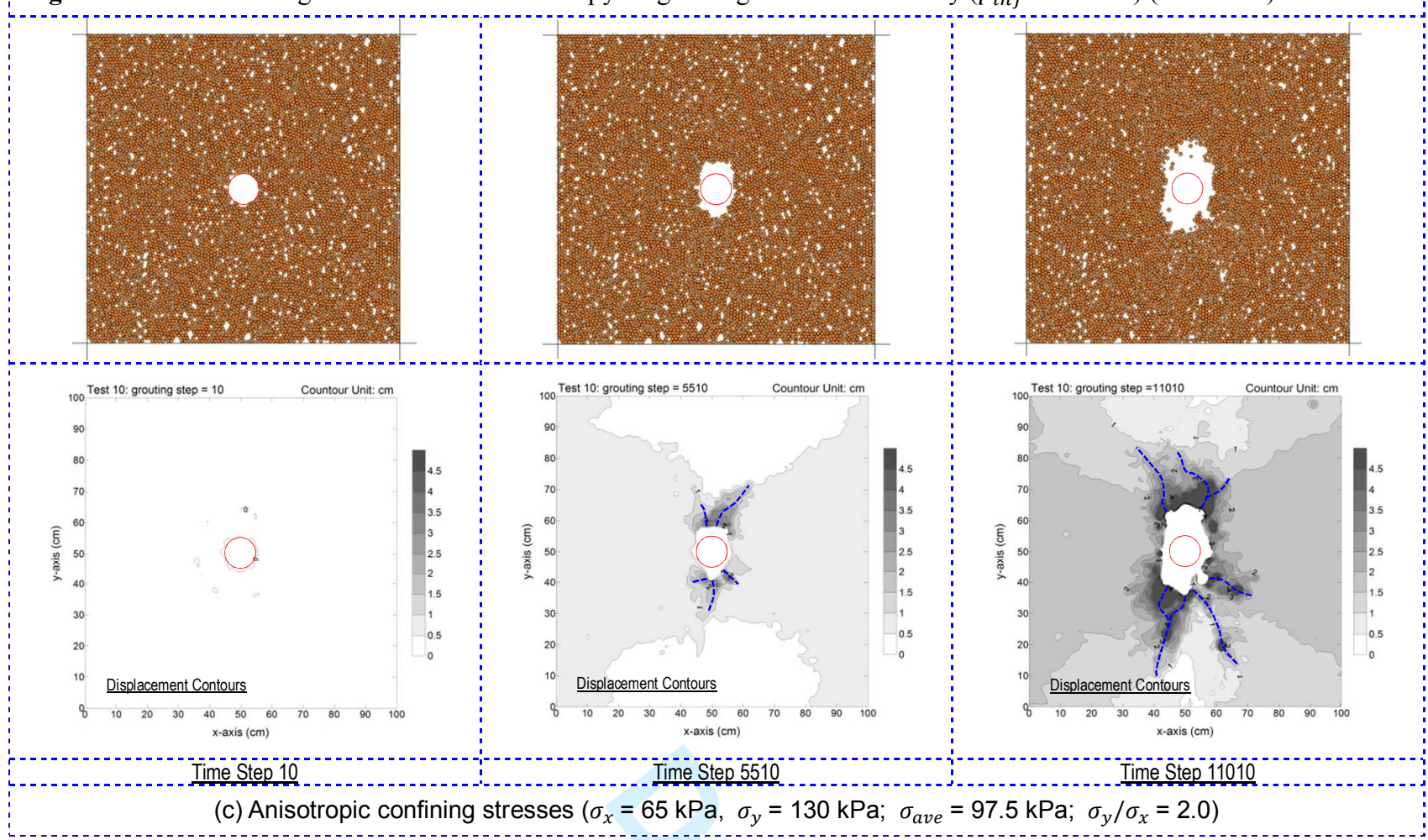


$<<$ Fig. $10>>$ - Results of numerical grouting in clay $\left(\mathrm{p}_{\mathrm{inj}}=350 \mathrm{kPa}, \sigma_{\mathrm{x}}=65 \mathrm{kPa}, \sigma_{\mathrm{y}}=130 \mathrm{kPa}\right)$.

Fig. 10. Results of numerical grouting in clay $\left(p_{i n j}=350 \mathrm{kPa}, \sigma_{x}=65 \mathrm{kPa}, \sigma_{y}=130 \mathrm{kPa}\right)$.

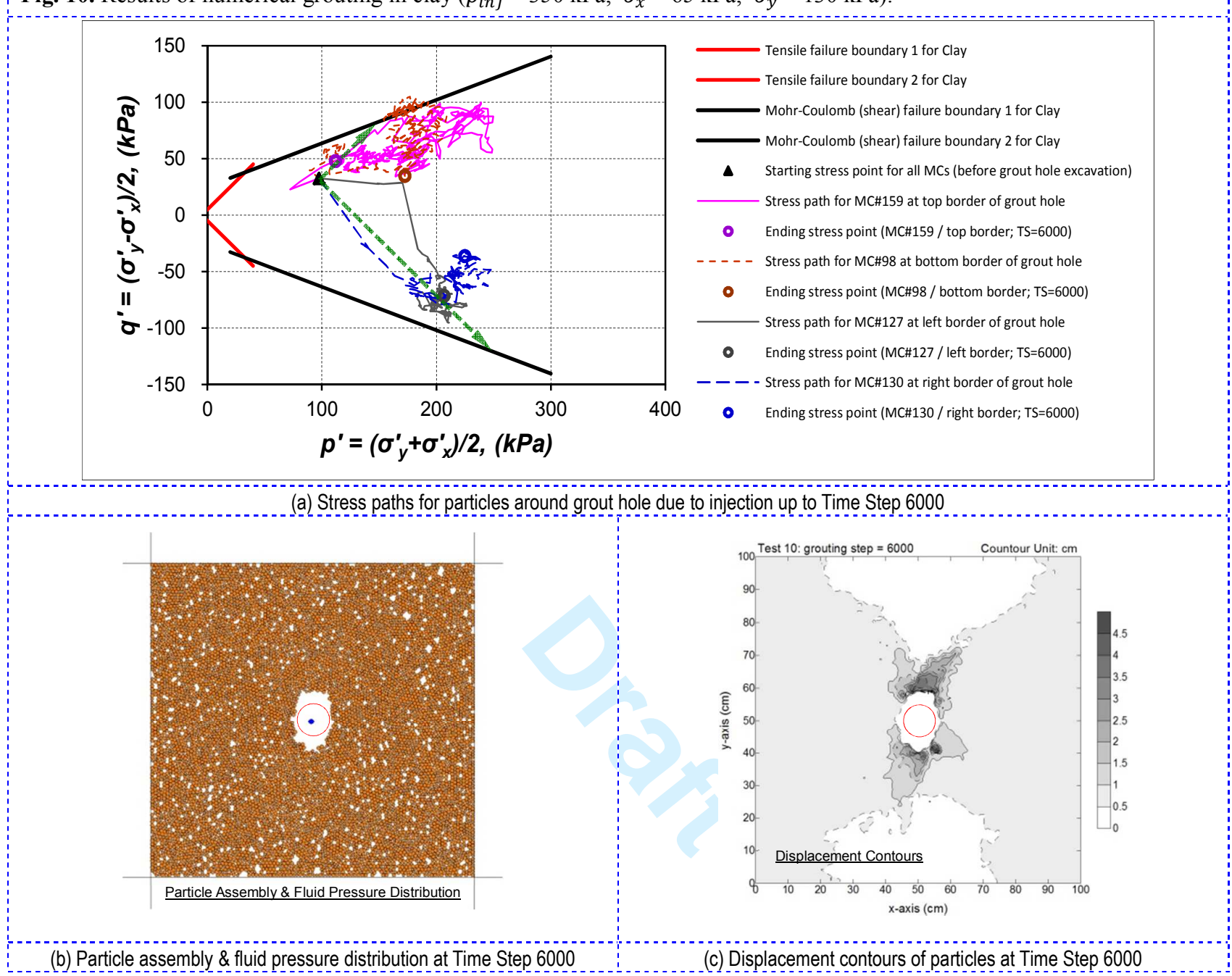


Fig. 10(a)

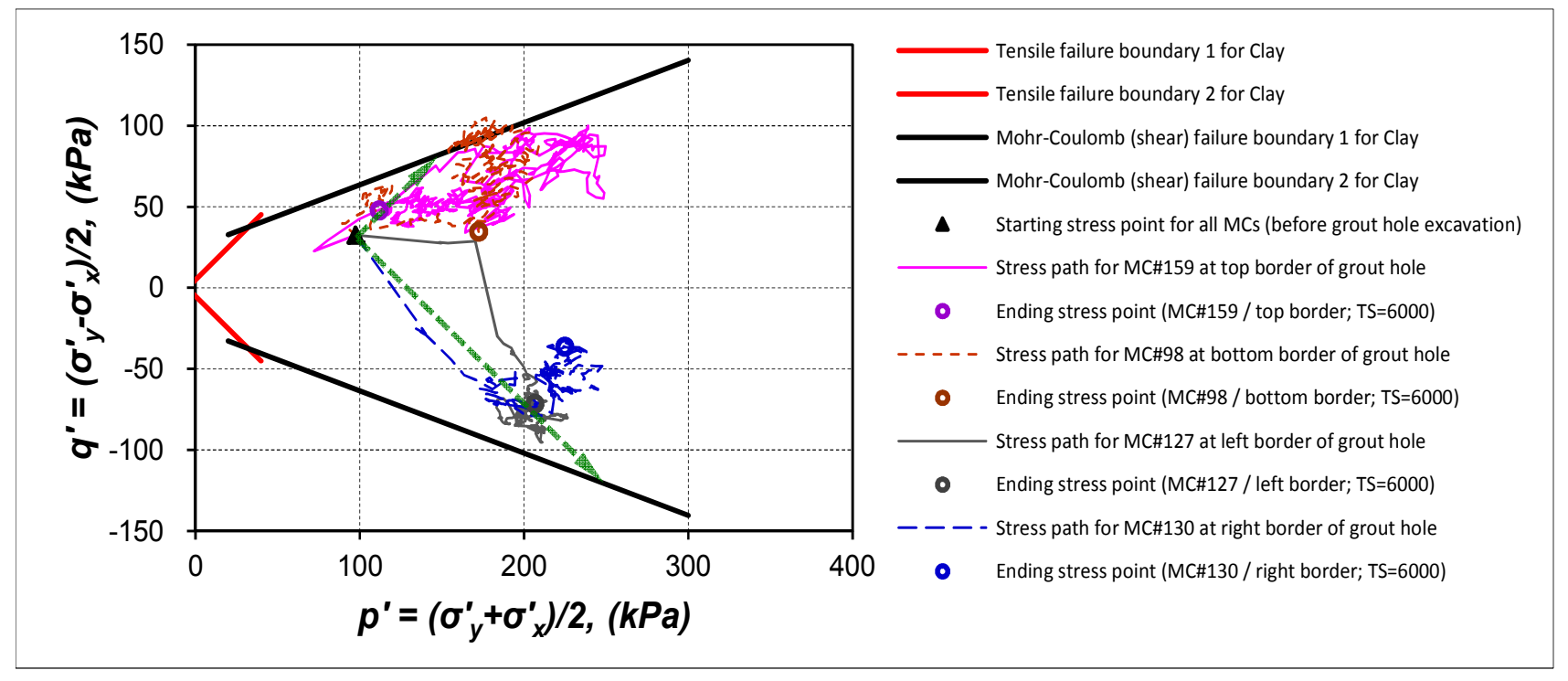


Figs. 10(b) \& 10(c)
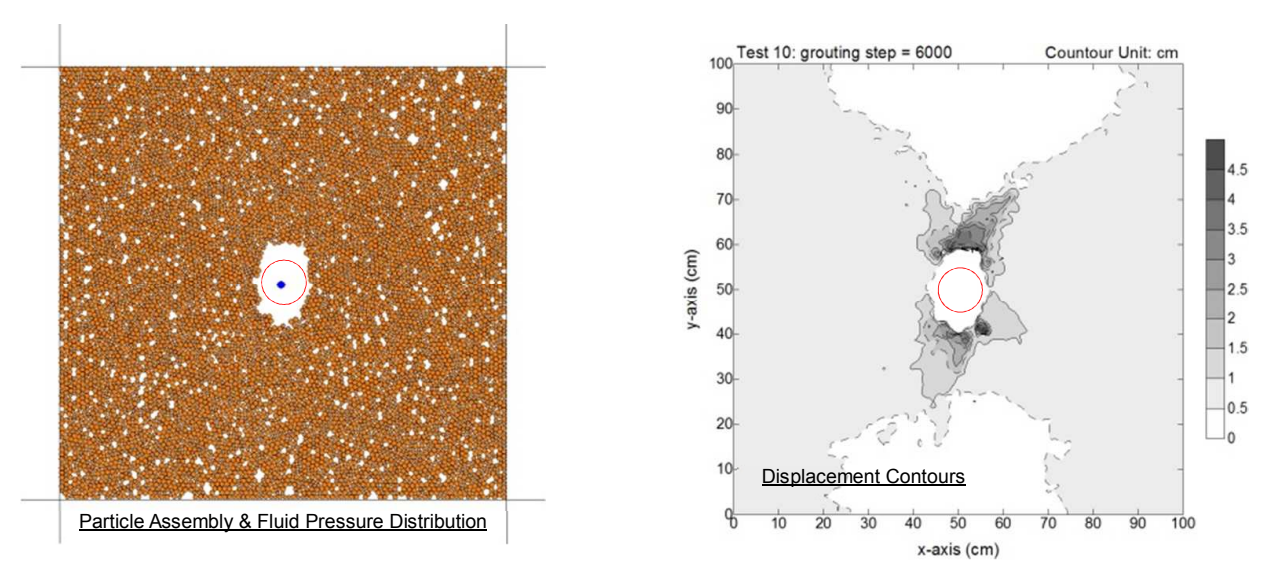
$<<$ Fig. 11 $>>-$ Results of numerical grouting in sand $\left(\mathrm{p}_{\mathrm{inj}}=350 \mathrm{kPa}, \sigma_{\mathrm{x}}=65 \mathrm{kPa}, \sigma_{\mathrm{y}}=130 \mathrm{kPa}\right)$.

Fig. 11. Results of numerical grouting in sand $\left(p_{\text {inj }}=350 \mathrm{kPa}, \sigma_{x}=65 \mathrm{kPa}, \sigma_{y}=130 \mathrm{kPa}\right)$.

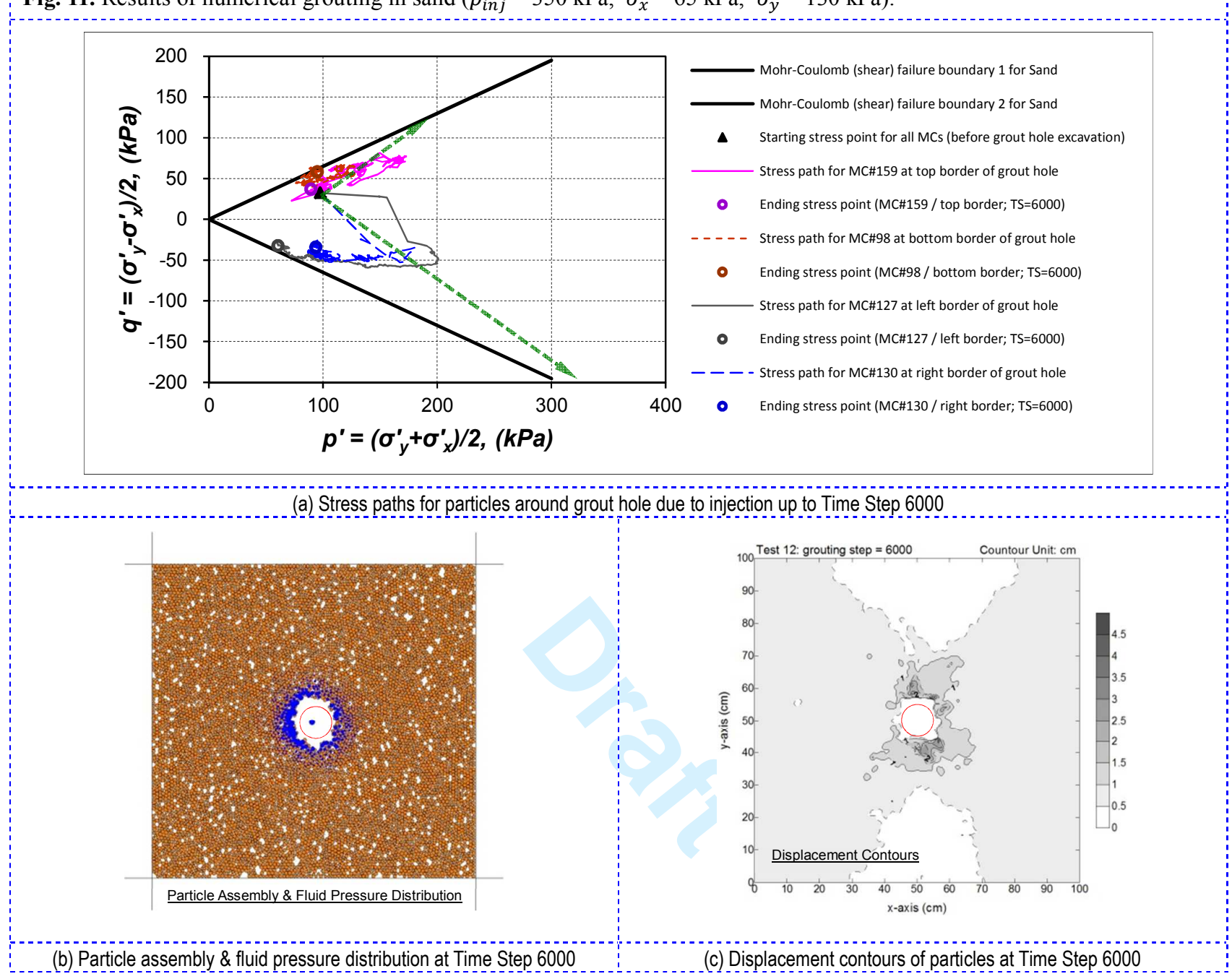


Fig. 11(a)

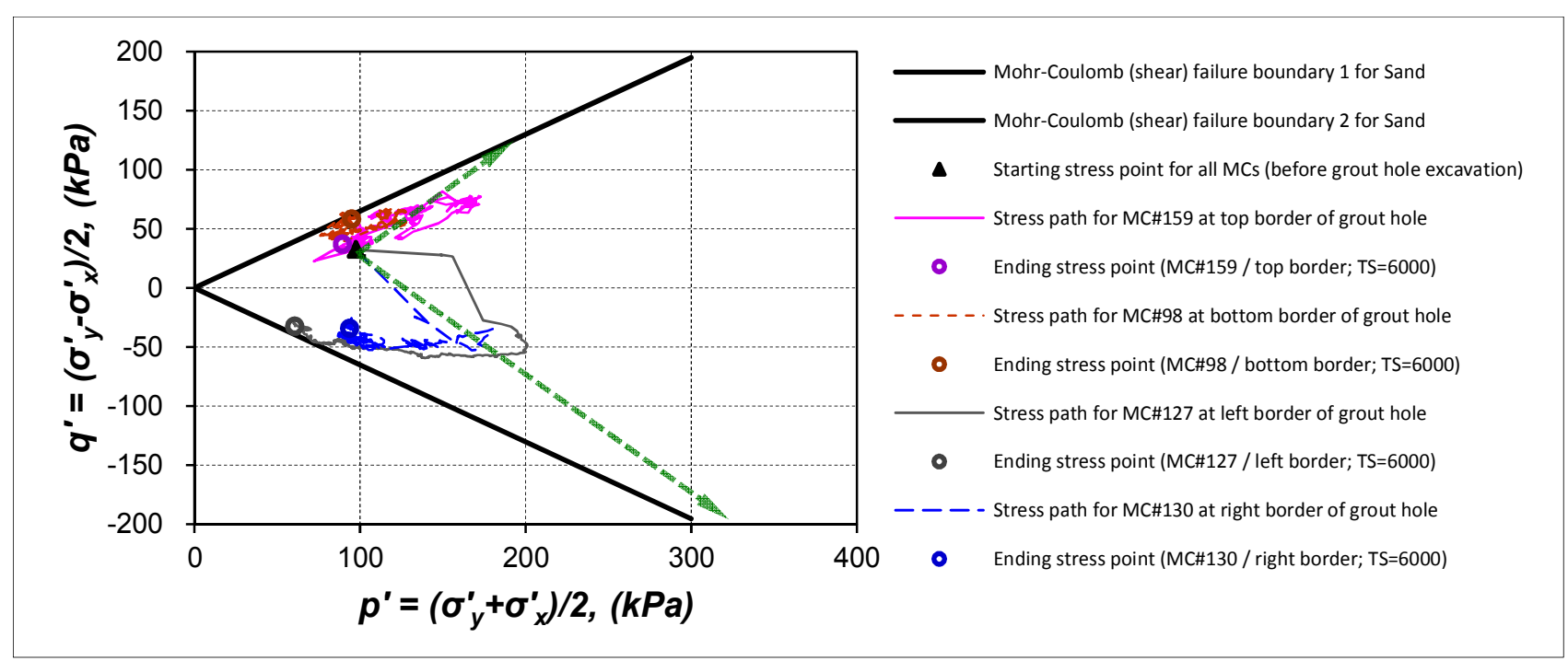


Figs. 11(b) \& 11(c)
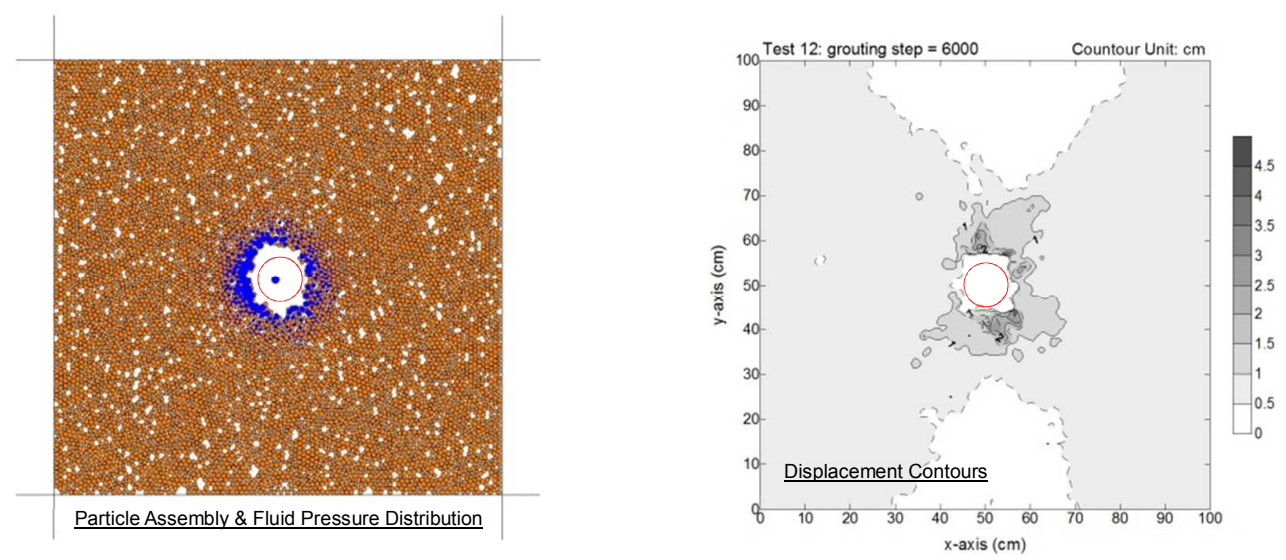
$<<$ Fig. 12>> - Proposed injection mechanism of hydraulic fracturing in soils.

Fig. 12. Proposed injection mechanism of hydraulic fracturing in soils.

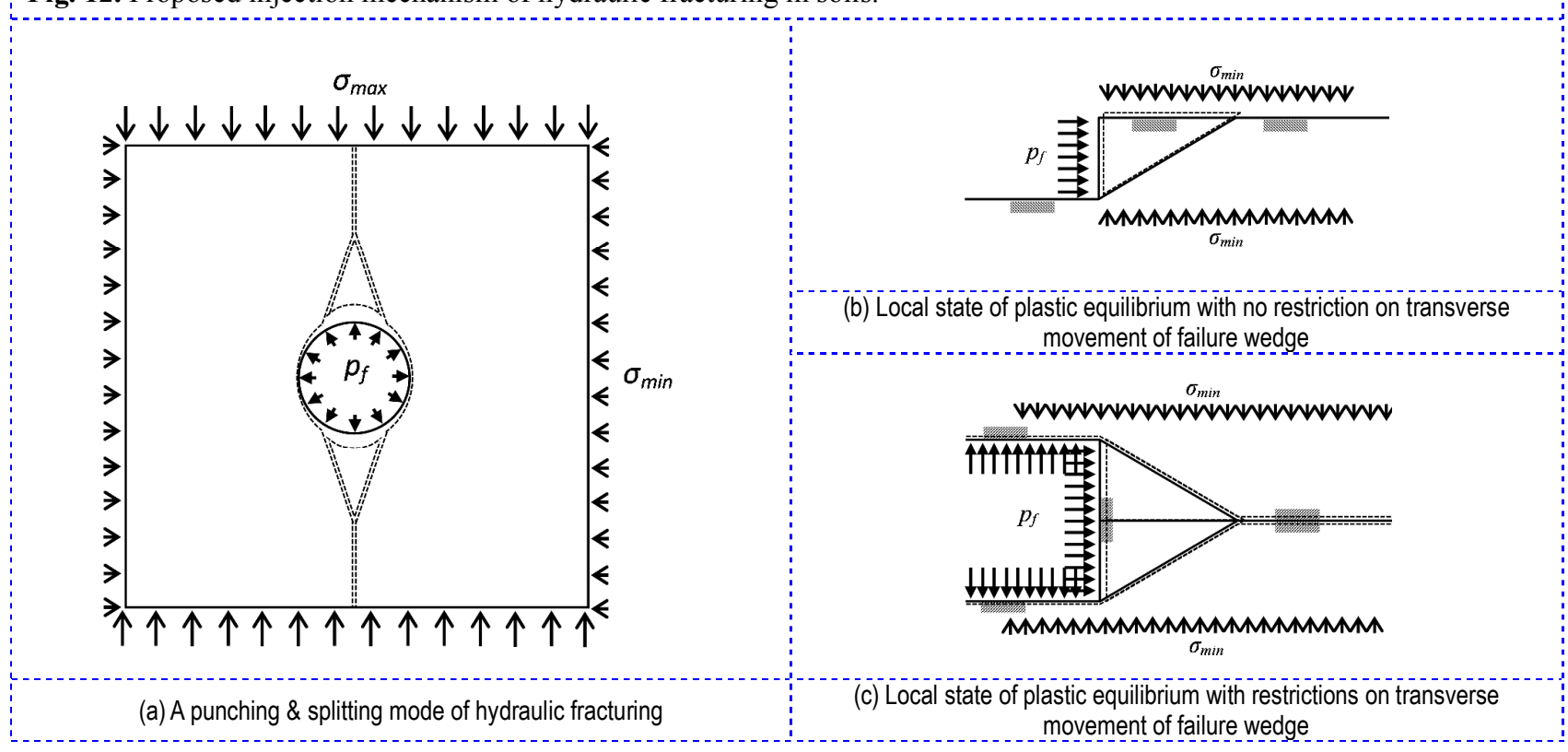


Fig. 12 (a)

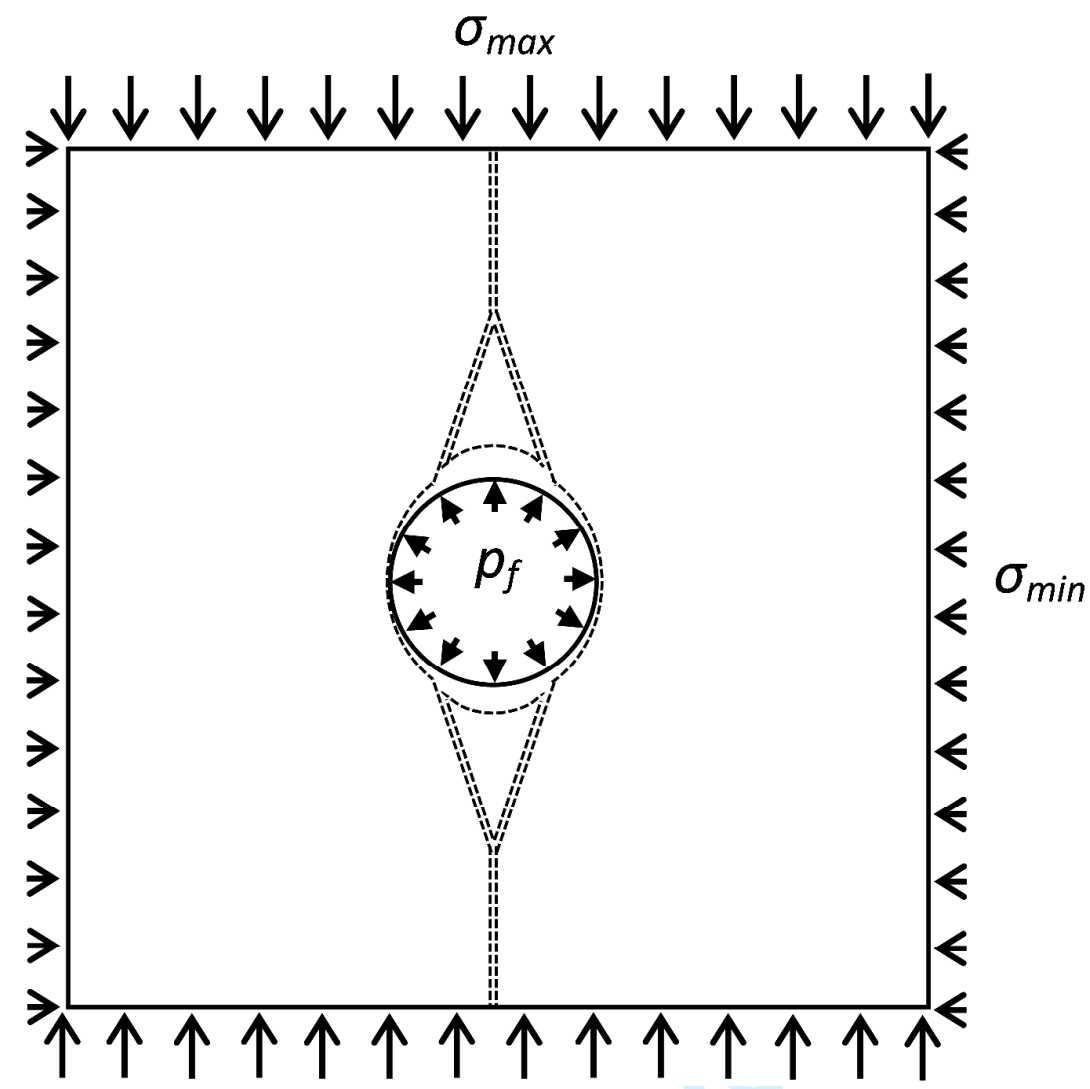


Fig. 12 (b)

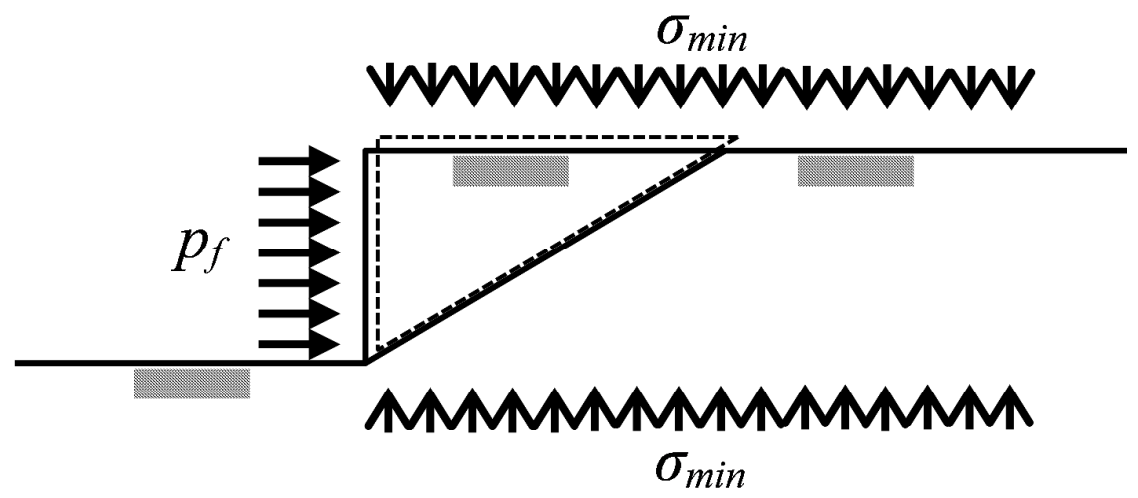


Fig. 12 (c)

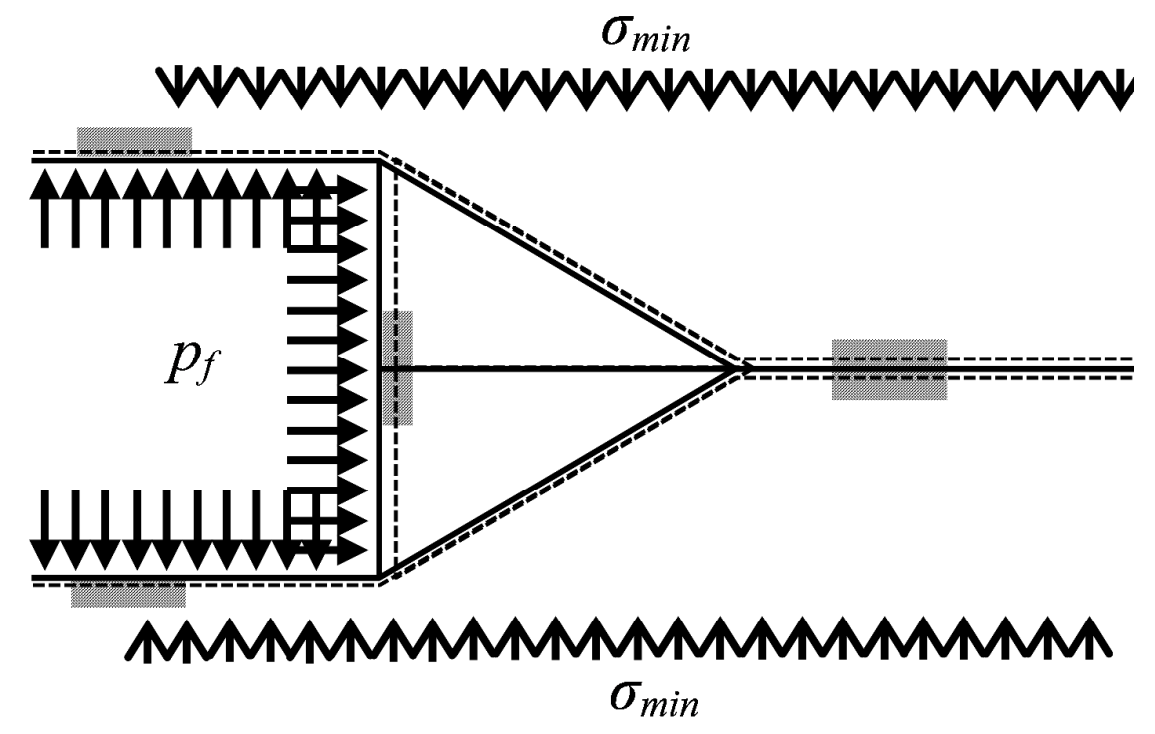

